Sugerencia de citación: Pérez-Torres,

F. J. (2022). Ocupación informal y formal en Colombia, equilibrios de largo plazo y principales causas históricas (2001-2019). Un análisis vectorial de corrección de errores. tiempo\&economía, 9(1), 41-103.

DOI:

https://doi.org/10.21789/24222704.1690

\section{Ocupación informal y formal en Colombia, equilibrios de largo plazo y principales causas históricas (2001-2019). Un análisis vectorial de corrección de errores}

Francisco José Pérez Torres

Economista con estudios de maestría en Teoría y Política Económica de la Universidad Nacional de Colombia y magíster en Ciencias Económicas de la Universidad Santo Tomás, Colombia. Asesor de la Facultad de Ingeniería de la

Universidad Nacional de Colombia https://orcid.org/0000-0001-8585-9399

fjperezt@unal.edu.co

*Una versión preliminar de este trabajo aparece en la serie FCE-CID 109 de la Facultad de Ciencias Económicas de la Universidad Nacional Colombia. 


\section{RESUMEN}

Este trabajo es una contribución al estudio de las relaciones de equilibrio entre la ocupación informal, el salario mínimo, el desempleo urbano, el empleo en los sectores de manufactura, comercio y servicios y el crecimiento económico. Con el objetivo de establecer la repercusión de estas variables en la variabilidad de la ocupación informal, a través de un modelo vectorial de corrección de errores se comprueba la existencia de relaciones de equilibrio de largo plazo entre las variables mencionadas. Con los resultados de impulso-respuesta y de descomposición de varianza, se muestra cómo estas responden, recíprocamente, ante choques estocásticos que puedan registrar. Los resultados econométricos se relacionan con importantes aspectos históricos estructurales del desarrollo de la economía colombiana, evidenciando implicaciones básicas para la formulación de políticas que buscan disminuir la economía informal y la ocupación generada en ella.

Palabras clave: economía informal, salario mínimo, desempleo urbano, empleo, modelo VEC, historia económica.

Códigos JEL: C32, E24, E26, J21, 017.

\section{ABSTRACT}

This work is a contribution to the study of the relationships of equilibrium between informal occupation, minimum wage, urban unemployment, employment in the manufacturing, trade and services sectors, and economic growth. In order to establish the impact of these variables on the changeability of informal occupation, the existence of long-term equilibrium relationships between them is verified through a vector error correction model. With the results for impulse-response and variance decomposition, it is identified that the variables above mentioned reciprocally respond to stochastic shocks they may experience. Econometric results are related to important historical and structural aspects of the development of the Colombian economy, showing basic implications for the formulation of policies intending to reduce informal economies and the employment generated by these.

Keywords: Informal economy, minimum wage, urban unemployment, employment, VEC model, economic history.

JEL Codes: C32, E24, E26, J21, O17. 


\section{INTRODUCCIÓN}

Pese a sus contraproducentes efectos sociales y económicos, las unidades productivas de la economía informal en Colombia cumplen un considerable papel en la producción de bienes y servicios y la generación de ingresos para las amplias capas de la población excluidas de la economía formal. Su contribución a la ocupación en el país alcanza ocho millones de personas, lo que sugiere que más que mitigar el desequilibrio de empleo en el mercado laboral, lo que mitiga es la debilidad que caracteriza a la economía colombiana, en su conjunto, en materia de absorción de fuerza de trabajo. Su contribución es tal, que sin economía informal la presión social sería difícilmente sostenible.

El alto nivel de ocupación que se crea en el ámbito de la economía informal por décadas ${ }^{1}$ viene haciendo parte de los problemas más relevantes de la economía colombiana. ${ }^{2}$ Para la política económica y social del país actual, este fenómeno cada vez acusa mayor importancia. Motivadas por el pensamiento económico neoclásico más ortodoxo, en Colombia son muchas las voces que señalan con diferentes discursos que la ocupación informal y el desempleo tienen como causa inmediata el salario mínimo y los elevados costos no salariales asociados a cargo de los empresarios. En consecuencia con los preceptos económicos neoliberales - firmemente fomentados por las principales entidades multilaterales prestamistas y por la OCDE-, las fórmulas de política económica adoptadas por las autoridades económicas del país en respuesta al problema de la ocupación informal se han enfocado en medidas orientadas a la eliminación de los aportes parafiscales sobre la nómina, así como la implementación de una política de manejo del salario mínimo que elimine su incremento gradual en términos reales, y, por supuesto, profundizando la política de flexibilización laboral. Lo cierto es que en los últimos treinta años la ocupación informal se ha mantenido en un nivel alto y la disminución registrada ha sido insubstancial, dando cuenta de la ineficacia de las medidas tomadas, que, entre otras cosas, casi siempre

El uso del espacio público por vendedores ambulantes es una clara y clásica expresión de la ocupación informal en las ciudades grandes e intermedias de Colombia. Para el caso de Bogotá, donde alrededor del $43 \%$ de los individuos ocupados están vinculados a la economía informal, ese uso del espacio es un problema permanente que se ha buscado resolver normativamente desde 1932.

2 En el país, la informalidad empieza a ser vista con particular atención desde mediados de la década de los setenta del siglo pasado. Planes de desarrollo como el "Plan para Cerrar la Brecha” (1975), el “Plan de Integración Nacional” (1980), "Cambio con Equidad” (1983), y en adelante todos, plantean estrategias de solución. 
han sido elaboradas omitiendo el núcleo duro de la informalidad, es decir, la ocupación por cuenta propia.

Adicional al hecho de que la correlación y la magnitud de los impactos entre la ocupación informal, el desempleo y el salario mínimo presentan ambigüedad teórica y la evidencia empírica no es concluyente, existen factores importantes - poco discutidos - que han obstruido los intentos de contrarrestar significativamente la economía informal y la ocupación originada en esta. Entre ellos están la falta de eficacia de las políticas públicas sociales, el mismo crecimiento económico y los problemas estructurales de la economía, que le impiden un eficientemente proceso de absorción de la fuerza laboral urbana. De tal forma se genera un círculo perverso entre la ocupación en el ámbito de la economía informal y las variables representativas de esos factores. Vale reiterar que los choques que se ocasionan en variables claves del mercado laboral formal, así como la especificidad del crecimiento de la economía y el alcance y la efectividad de la política pública laboral, actúan como importantes catalizadores de la dinámica de la ocupación informal.

En materia de la evaluación de políticas económicas enfocadas a disminuir la ocupación informal, es importante analizar y, especialmente, cuantificar y precisar estadísticamente los movimientos y las respuestas que se registran entre la ocupación generada en la economía informal ante los choques que experimenten variables claves del mercado laboral formal, como el desempleo, la ocupación formal, el salario mínimo y el crecimiento económico expresado en el comportamiento del PIBr. Con el objeto de identificar y analizar las fuentes de variación de la ocupación en el ámbito de la economía informal en Colombia, en este trabajo se emplea un modelo vectorial de corrección de errores (MVCE), que junto con el análisis de impulso respuesta y el procedimiento de descomposición de varianza en el error de predicción, permiten dilucidar y cuantificar con precisión los efectos y la importancia estadística de los choques estocásticos en las variables que influyen la ocupación que se causa en la economía informal.

Además de la introducción, este trabajo contiene ocho secciones principales. La primera se centra en el marco conceptual que orienta el análisis. La siguiente sección, de contextualización, describe la magnitud y las características actuales de la ocupación dentro de la economía informal del país. Posteriormente, se presenta una revisión de antecedentes que discute los resultados encontrados en diversos estudios alrededor de los determinantes considerados como los principales referentes para explicar la ocupación 
en la economía informal; estos son el desempleo urbano, el salario mínimo y el crecimiento económico. Adicionalmente, se examina la efectividad que han tenido algunas de las medidas de política económica implementadas entre 2002 y 2019 para disminuir la ocupación informal. En la sección inmediatamente después se describen las series de datos utilizadas, mientras que en la sección posterior a esta se explica el MVCE utilizado para el análisis del empleo generado en el campo de la economía informal en Colombia. La sección que sigue presenta el análisis de los resultados obtenidos relacionados con el orden de integración de las variables y las relaciones de cointegración subyacentes entre las variables que conforman el modelo de análisis. En esta sección también se presenta el análisis de los coeficientes del vector de cointegración, de los coeficientes de velocidad de ajuste y de las pruebas econométricas de las restricciones que se les imponen, así como el análisis de los resultados de las funciones impulso respuesta y descomposición de varianza. Finalmente, las dos últimas secciones presentan, respectivamente, el diagnóstico del modelo y las principales conclusiones derivadas del estudio, las cuales contribuyen a explicar cómo la ocupación originada en la economía informal hunde sus raíces en la estructura histórica que se fue formando a lo largo del proceso de desarrollo y crecimiento de la economía del país en los últimos 100 años.

\section{MARCO CONCEPTUAL}

Sin desconocer los factores institucionales ${ }^{3}$ presentes en la economía colombiana, el marco teórico que sustenta este trabajo atribuye la existencia de la economía informal y la ocupación derivada de ella fundamentalmente a factores estructurales de la economía colombiana. Es un segmento de la economía que no es residual, tiene dinámica propia y múltiples vínculos con la economía formal, es decir, no es un fenómeno económico exclusivo del mercado laboral, como usualmente se presenta y se discute. En este orden, aunque el objeto de este trabajo es el análisis de la ocupación en el ámbito de la economía informal, conceptualmente es importante aclarar a que se refieren estas dos categorías. El concepto de economía informal normas legales determina la elección del individuo de ser o no formal, subestimando, en cierta forma, que centenares de miles de individuos se ocupan en el ámbito de la economía informal porque no tienen libertad de elección entre opciones diferentes, es decir, más que por una decisión racional, dadas las circunstancias económicas se ven compelidos a ejercer una actividad económica informal. 
hace referencia a las actividades económicas que incluyen tanto las relaciones de producción establecidas por las unidades de producción informales dentro del proceso de producción, cambio, distribución y consumo de bienes y servicios, como las relaciones de ocupación adquiridas dentro de tales unidades. De otra parte, puesto que estar ocupado y estar empleado, teóricamente, no tienen igual significado económico, se debe subrayar que en el ámbito de la economía informal la ocupación generada se materializa en actividades que, a través de un negocio, tienen por objeto la producción y comercialización de bienes y servicios para atender una demanda final interna del país, propia del consumo de los hogares. En contraste, en el ámbito de la economía formal el empleo generado es resultado de una transacción en el mercado laboral, donde concurren oferentes y demandantes con el único fin de transar un único bien básico de producción, es decir, el trabajo asalariado; por supuesto, todo circunscrito a un nexo jurídico entre trabajadores y empleadores, el cual está integrado y funciona para el sector más desarrollado de la economía.

Entendida así, la "informalidad" es un fenómeno transversal a la economía que permea todas sus ramas de la producción (exceptuando contadas actividades), especialmente la industria, el comercio y los servicios. Las actividades productivas de esas unidades económicas y de los que allí ejercen una ocupación no se asocian con un único sector. Por consiguiente, la economía informal, más que un "sector" en el sentido de grupo industrial o actividad económica específica, es el conjunto de empresas tanto urbanas como rurales que operan en la esfera informal, sin el apoyo del Estado y al margen de las normas jurídicas que regulan la economía.

Exceptuando salud, educación, comunicaciones y gobierno, donde la participación puede ser nula, una unidad económica informal realiza casi todo tipo de actividad productiva. Dependiendo del nivel de pobreza, algunas operan sin tener una ubicación fija, así como en las viviendas de los hogares, mientras que otras unidades, con más recursos, operan en locales, oficinas y talleres pequeños.

Para una parte de los ocupados informales las actividades de producción y servicios para transar en el mercado son amplias y variadas, de poco valor agregado e ingresos, operan con habilidades mínimas y, sobre todo, con escaso o ningún capital, v. g., las actividades de servicio de mototaxismo, a domicilio, de limpiabotas, servicios domésticos remunerados empleados por los hogares, producción y ventas ambulantes de alimentos, 
producción de material reciclado, producción y servicios de jornaleros de la construcción y agricultura, entre otras. Sin duda, estas son actividades que carecen de barreras de entrada. Sin embargo, las actividades de determinadas unidades emplean cierta cantidad de inversión y nivel de especialización, ${ }^{4}$ como los servicios profesionales y la producción de artefactos que demandan conocimientos técnicos, por lo que, en efecto, cuentan con barreras de entrada. En síntesis, de lo anterior se sigue que las actividades asociadas a los dos segmentos de la ocupación creada en la economía informal se diferencian por la existencia o no de barreras de entrada y porque en uno de ellos no operan exclusivamente los individuos menos educados y productivos.

Para un amplio segmento, las unidades productivas informales, las de menor calificación, son operadas por un solo individuo, es decir, son negocios unipersonales que en ocasiones trabajan con la ayuda de familiares no remunerados. El otro segmento de unidades opera como empresas de propietarios informales no constituidas en sociedad, teniendo como característica principal que pueden contratar cierta cantidad de asalariados (Comisión Europea et al., 2008). De tal forma, las dos unidades productivas básicas de la economía informal están constituida por las empresas informales no constituidas en sociedad sin asalariados y por las empresas de empleadores informales (empresas no constituidas en sociedad) con asalariados (Comisión Europea et al., 2008). Es claro que ambas unidades de negocio difieren por el tipo de unidad de producción y por la posición de los individuos dentro de la ocupación.

En Colombia, los individuos vinculados al primer tipo de unidad informal productiva son los ocupados por "cuenta propia", mientras que los vinculados al segundo tipo son los llamados "patronos" o "empleadores", propietarios de unidades económicas productoras de bienes y servicios con máximo nueve empleados. Así mismo, son dueños de los medios de producción con los cuales desarrollan su actividad económica, es decir, de la materia prima, las herramientas, los equipos, la maquinaria, los vehículos y las instalaciones con las cuales desarrollan su negocio (DANE, 2020). En el

\footnotetext{
Existe consenso en que para la actividad que realizan las empresas informales (empleadores) es apropiada la frontera de producción del Sistema Nacional de Cuentas (SCN). Lo que significa que la producción de estas unidades económicas implica un proceso físico, realizado bajo su responsabilidad, control y gestión, en el que se utilizan mano de obra y activos para transformar insumos de bienes y servicios en productos de otros bienes y servicios. Todos los bienes y servicios producidos se pueden vender en el mercado. El SCN incluye dentro de la frontera de producción toda la producción realmente destinada al mercado para su venta (Comisión Europea et al., 2008).
} 
país, tales unidades participan marginalmente en el mercado laboral, donde la demanda de fuerza de trabajo para el desarrollo de sus actividades puede ser contratada formal o informalmente.

Para el análisis desarrollado a lo largo de este documento, se destacan cuatro elementos conceptuales derivados de lo expuesto en esta sección. Primero, en contraste con el nivel de los ocupados por cuenta propia, el nivel de los ocupados como patronos o empleadores, además de ser el segmento de menor peso dentro de la ocupación generada en la economía informal, tienen un perfil empresarial manifiesto en toda la cadena de operación. Segundo, debido a que los bienes y servicios derivados de las actividades productivas de los individuos ocupados como cuenta propia se transan en el mercado interno de consumo de los hogares, en este estudio no se les considera trabajadores del mercado laboral formal, sino agentes productores que realizan su intercambio mercantil con los consumidores en la esfera de la economía informal, que, por supuesto, es una institución informal (North, 1993). Tercero, con base en esta diferencia, el concepto apropiado es el de ocupación informal causada en la economía informal, en lugar de "mercado laboral informal", concepto suigéneris respecto al significado teórico de un mercado como institución, ya sea formal o informal (Ayala, 2000). Cuarto, de acuerdo con lo expuesto en esta sección, se reitera la opinión de aceptación general según la cual no todos los ocupados en la economía informal son pobres y —como la pobreza no se limita solo a la informalidad - no todos los ocupados pobres laboran en la economía informal. En este sentido, se considera que quienes operan en la economía informal como empleadores de otros trabajadores pueden ser menos pobres o no pobres, mientras que algunos trabajadores asalariados formales son pobres. Sin embargo, lo que sí coincide significativamente es ser un individuo ocupado por cuenta propia en la economía informal y a la vez ser pobre o pobre extremo (Bosh \& Maloney, 2008; Bourguignon, 1979; García, 1999).

\section{OCUPACIÓN GENERADA EN LA ECONOMÍA INFORMAL COLOMBIANA}

En Colombia, desde inicios de los años 70 del siglo pasado hasta lo corrido del presente siglo, las unidades productivas de la economía informal han desempeñado un importante papel en la generación de bienes y servicios y de ingresos. Si bien es cierto que el Departamento Administrativo 
Nacional de Estadística (DANE) no ha establecido con certeza cuál es su contribución al PIB del país, sí muestra, a través de la gran encuesta integrada de hogares (GEIH), su enorme contribución a la ocupación actual (cerca de 8 millones de ocupados), lo que sugiere que su importancia, más que mitigar el desequilibrio de empleo en el mercado laboral, está en atenuar la debilidad que caracteriza a la economía colombiana, en su conjunto, en materia de absorción de fuerza de trabajo. Tanto es así que sin economía informal la presión social y, sobre todo, la presión sobre mercado laboral ejercida por altas tasas globales de participación y bajas tasas de ocupación serían difícilmente sostenibles, pues se trataría de cerca de dos millones de hogares sin trabajo y sin ingresos.

En efecto, con base en la Encuesta de Micronegocios enero-octubre 2019 (DANE, 2020), la tabla 1 muestra para el área urbana ${ }^{5}$ las características actuales más relevantes de la ocupación creada en la economía informal. Diferenciando las unidades económicas entre negocios de propietarios cuenta propia y empresarios empleadores, se observa el nivel profundización de formalización, ${ }^{6}$ según los aportes a salud y pensión por parte de los agentes de la economía informal, así como la tenencia del Registro Único Tributario (RUT) y del registro en Cámara de Comercio, y el sitio donde operan. Adicionalmente, en la parte inferior de la tabla se muestran las cifras relativas a la ocupación y a los puestos de trabajo generados en ambos segmentos de la economía informal, según lo reportado por la GEIH de 2019, cuarto trimestre (DANE, 2019). De acuerdo con las cifras reportadas, en el país existen 4,9 millones de unidades económicas pertenecientes a negocios de propietarios cuenta propia y 0,7 millones de empresas informales de propietarios empleadores. En su mayoría, estas transan sus bienes y servicios en comercio, mantenimiento y reparación (30\%), agricultura $(22,1 \%)$ e industria $(12,3 \%)$. Le siguen hotelería y restaurantes $(8,1 \%)$, transporte $(8 \%)$, recreación $(6,5 \%)$ y construcción $(5,9 \%)$. En el extremo, la menor participación de sus transacciones se registra en actividades de correo y

5 El fenómeno no es exclusivo del área urbana. De hecho, según cifras de la GEIH, en el sector rural, en promedio, alrededor del $85 \%$ de las actividades económicas se basan en ocupación informal, con notable participación de los ocupados por cuenta propia, y pese a que existen muchas empresas formales lo común es eludir el establecimiento de relaciones obrero-patronales formales.

6 El CONPES 3956 de 2019 sobre formalización empresarial estableció cuatro puntos para identificar el grado de formalidad: i) la existencia de la empresa que implica tener registro empresarial; ii), la formalidad de insumos y factores de producción utilizados por la empresa, que impone el aseguramiento de los trabajadores a través de los aportes a salud, pensión y ARL; iii), la formalidad en los procesos de producción y comercialización de bienes y servicios; y iv) la formalidad tributaria, que implica la declarar y pagar impuestos. 
telecomunicaciones $(1 \%)$, minería $(0,9 \%)$, servicios sociales de salud $(0,8 \%)$ y educación $(0,7 \%)$.

\begin{tabular}{|c|c|c|}
\hline \multirow{3}{*}{ Concepto } & \multicolumn{2}{|c|}{ Unidad económica } \\
\hline & Cuenta propia & Empleadores \\
\hline & \multicolumn{2}{|c|}{ Porcentaje } \\
\hline Unidades económicas & 86,6 & 13,2 \\
\hline \multicolumn{3}{|l|}{ Empleo } \\
\hline 1 persona & 77,2 & \\
\hline 2 a 3 personas & & 18,6 \\
\hline entre 4 y 9 & & 4,1 \\
\hline Aportes a salud y pensiones & 7,9 & 25,3 \\
\hline ARL & 5,1 & 19,5 \\
\hline RUT-CC & 27,1 & 66,4 \\
\hline \multicolumn{3}{|l|}{ Ubicación de la empresa } \\
\hline Vivienda & 32,5 & 19,5 \\
\hline Local (tienda, taller, fabrica, oficina, consultorio) & 14,9 & 46,1 \\
\hline Domicilio & 21,3 & 11,5 \\
\hline Ambulante & 13,4 & 4,4 \\
\hline Vehículo con o sin motor & 11 & 3,4 \\
\hline \multicolumn{3}{|l|}{ Empleo** } \\
\hline Ocupación total Cabecera & 17,9 & \\
\hline \multicolumn{3}{|l|}{ Puestos de trabajo generados en la Economía } \\
\hline Informal & 9,13 & \\
\hline $\begin{array}{l}\text { Puestos de trabajo generados según posición } \\
\text { dentro de la Economía Informal }\end{array}$ & 8,5 & 0,63 \\
\hline Porcentaje & $93.1 \%$ & $6.9 \%$ \\
\hline
\end{tabular}

*Fuente: Dane, Encuesta de Micronegocios 2019

**Fuente: Dane, Gran Encuesta Integrada de Hogares, 2019

Es claro que dentro de la economía informal predomina el segmento de unidades económicas informales de personas ocupadas por cuenta propia. Las cifras sobre sus aportes a la seguridad social, el registro tributario y de afiliación a cámara de comercio demuestran bajos niveles de formalización. Así mismo, el sitio donde funcionan estas unidades corresponde, en primer lugar, a la vivienda, seguido por actividades de domicilios, locales, vendedores ambulantes y en vehículos con o sin motor. Es propio de estas unidades un bajo nivel de organización, nula división entre trabajo y capital, producción en pequeña escala y, cuando existen, relaciones laborales sustentadas en el empleo ocasional, el parentesco o las relaciones personales, con total ausencia de garantías formales (OCDE, 2007). En contraste, para las unidades económicas informales de los empleadores, se advierte un perfil empresarial más definido. En efecto, comparando con las unidades cuenta propia, emplean hasta 9 trabajadores. Así mismo, según sus aportes a la seguridad social y la tenencia de registros legales, exhiben mayor
Tabla 1. Características actuales de la informalidad urbana en Colombia (2019)* 
profundización de formalización y sus unidades, que son menos precarias, funcionan en locales en las modalidades de tienda, taller, fábrica y oficina.

Por otra parte, la GEIH del cuarto trimestre de 2019 muestra que más del $50 \%$ de la ocupación urbana total se origina en el ámbito de la economía informal, y que de los 9,13 millones de puestos de trabajo generados aquí, 93,1 \% corresponde a unidades económicas por cuenta propia; el resto (0,63 millones) corresponde al empleo generado por las empresas informales de empleadores. Aquí vale subrayar que pese a que en la segunda década del presente siglo la ocupación originada en la economía informal urbana ha registrado cierta disminución, las cifras actuales advierten que ostenta un nivel realmente alto. Así durante 2009-2012 se ubicó en 55 \%; posteriormente, en el período 2013-2015, el promedio cayó hasta 52,5 \% y entre 2016-2019, si bien disminuyó, se mantuvo en $51 \%$.

Por último, aunque en la más reciente información de micronegocios reportada por el DANE en 2020 no se muestran los niveles de ingresos de los empleadores y cuenta propia, conviene recordar que los ingresos de los primeros son muy superiores a los de los segundos. ${ }^{7}$ De hecho, la encuesta a microempresarios de 2015 revela que el 42,3\% de los negocios cuenta propia perciben ingresos mensuales menores a 1 SMMLV, el 24,4 \% tiene ingresos mensuales entre uno y dos SMMLV y el 33,3\% más de dos SMMLV, ${ }^{8}$ que son los percibidos por los empleadores.

Lo relevante de las cifras expuestas es que dejan ver que las unidades productivas informales donde se ocupan los trabajadores por cuenta propia no solo constituyen el segmento de la economía informal más pobre dado sus actividades productivas de subsistencia, sino que además es el segmento de mayor peso, es decir, dentro del conjunto de los ocupados informales, el segmento de los cuenta propia conforma el núcleo duro de la ocupación generada por la economía informal, que históricamente ha representado cerca del $90 \%$ de la informalidad en el país. Sin duda, disminuir significativamente la ocupación informal implica que este núcleo sea atendido prioritariamente por la política pública.

$7 \quad$ La disparidad de ingresos, en el caso de los ocupados por cuenta propia, obedece a que el tipo de producto ofrecido o su baja calidad enfrenta una demanda de muy baja elasticidad-ingreso, contrario a lo observado con los patronos, quienes con la incorporación de alguna tecnología a los bienes y servicios que producen pueden atender una demanda elástica al ingreso.

8 Es importante mencionar que cuando se examina con detalle la información de ingresos de los empleadores se pueden construir rangos de ingresos mayores a tres, cuatro y hasta más de 10 SMMLV. 


\section{ANTECEDENTES}

Entre mercado laboral formal y economía informal existe un importante vínculo, manifiesto en los impactos producidos por los choques de demanda y oferta del primer mercado sobre la ocupación del segundo. En Colombia, son muchas las voces que señalan que la persistencia de la ocupación informal (y las altas tasas de desempleo) se debe fundamentalmente a los elevados costos no salariales que soportan los empresarios, distintos a la remuneración directa (salud, pensiones, cesantías, intereses sobre cesantías, prima de vacaciones, prima legal y cajas de compensación). Sin embargo, al mismo tiempo, es conveniente recalcar que también existen otros importantes factores de carácter históricos y de coyuntura que, sin duda, en los últimos veinte años han imposibilitado reducir sustancialmente la economía informal y la ocupación derivada de ella. Tales factores son básicamente tres: (i) los asociados con la falta de eficacia de las políticas públicas contra la informalidad, (ii) los irregulares y recurrentes impactos del crecimiento económico en el empleo y (iii) la débil capacidad de la economía, ${ }^{9}$ que históricamente ha impedido un eficientemente proceso de absorción de la creciente fuerza laboral urbana, originando así un permanente nivel de marginalidad ocupacional y de desempleo que nutren la economía informal. Significa esto que la conjunción de los tres factores, reflejados en los movimientos de variables claves del mercado laboral formal, han determinado no solo la dinámica y la trayectoria de la ocupación en la economía informal, sino también la dificultad para disminuirla en lo corrido del presente siglo.

A continuación, se examinan las evidencias empíricas de una serie de estudios que dan cuenta de la relación entre la ocupación en la economía informal y las variables de desempleo, salario mínimo y PIB como variable representativa del crecimiento económico.

\section{Tránsito del desempleo hacia la economía informal}

Una importante relación entre desempleo urbano y economía informal consiste en que un número de individuos se ve constreñido a incorporarse en ella debido a que una vez que las empresas agotan su capacidad de absorción (la demanda de trabajo se cubre) pierden la oportunidad de encontrar un empleo y, por sus características socioeconómicas particulares, tampoco pueden emprender una actividad empresarial en la economía

9 Este es un hecho generalmente menospreciado e ignorado en los estudios realizados en el país que explican la persistencia de la economía informal y la ocupación por ella generada. 
Tabla 2. Coeficientes estacionales de ocupación informal y de desempleo urbano (2001.I-2019.IV)

Fuente: elaboración propia. formal. Aunque no se sabe cuál es el tamaño o la cantidad de desempleados que fluyen hacia la informalidad, es importante ver que no todos ellos se convierten en informales y que ese paso tampoco es directo e inmediato, porque normalmente se registra gradualmente durante varios trimestres del año, dependiendo de la dinámica de la demanda laboral de las empresas. Es pertinente señalar que la importancia de dilucidar este punto está en que contribuye a entender y precisar (sin exagerar) el impacto efectivo que tiene el desempleo urbano sobre la ocupación creada en la economía informal.

Para ilustrar lo anterior, en la tabla 2 se presentan los coeficientes estacionales de la informalidad y el desempleo urbano trimestral en Colombia, calculados a partir de datos trimestrales desde 2001 hasta 2019. Se observa que los coeficientes trimestralmente se mueven inversamente, lo que hace que la temporada de desempleo más alta se asocie con la temporada más baja de ocupación en la economía informal, mientras que la temporada de desempleo más baja se asocie con la temporada más alta de ocupación en la economía informal. De acuerdo con los coeficientes, el desempleo registra la temporada más alta en el primer trimestre, mientras que las temporadas de bajo desempleo se inician en el segundo trimestre, continuando así hasta el cuarto trimestre, que es cuando se registra el menor nivel de desempleo.

\begin{tabular}{ccc}
\hline \multirow{2}{*}{ Trimestre } & \multicolumn{2}{c}{ Coeficientes estacionales } \\
\cline { 2 - 3 } & Ocupación Informal & Desempleo \\
\hline I & $-221,1$ & 219,0 \\
II & $-12,1$ & $-16,9$ \\
III & 1,8 & $-41,1$ \\
IV & 231,4 & $-160,9$ \\
\hline
\end{tabular}

Al mismo tiempo, los coeficientes de ocupación muestran que los dos primeros trimestres corresponden a temporadas de baja ocupación en la economía informal, mientras que el tercero y el cuarto corresponden a las más altas temporadas. Como ya se indicó, este comportamiento se explica porque en el cuarto trimestre de todos los años los empresarios tienen casi totalmente satisfecha su demanda de trabajo, es decir, no tienen necesidad de contratar mano de obra adicional, o si contratan, es muy poca.

Los coeficientes estacionales ayudan a comprender que en un escenario donde, por el lado de la oferta, se registra una alta tasa global de participación y, por el lado de la demanda, una tasa de ocupación saturada, junto con una tasa de desempleo elevada, puede suceder que una parte 
de los desempleados que no se pueden permitir estar en esa condición se vean obligados a incorporarse a la economía informal. Lo anterior deja ver que la mayoría de desempleados no transitan inmediatamente hacia la esfera de las actividades informales porque muchos, hasta donde su salario de reserva lo permita y por diversas razones, siguen buscando trabajo como cesantes y permanecen en el mercado laboral, mientras que aquellos que se incorporan, en el curso del tiempo, a la economía informal ya no hacen parte del mercado laboral sino del mercado interno, donde a través de un negocio transan sus bienes y servicios para proveerse de ingresos; es decir, son unidades económicas que operan en un mercado de bienes y servicios donde operan como productores, y como tal deben ser identificadas y evaluadas para efectos de política pública. Sin embargo, para establecer la magnitud de las respuestas y los impactos sobre los puestos de trabajo generados dentro de la economía informal, originados en este flujo, también es importante explorar hasta qué punto inciden los movimientos del empleo formal registrados en los sectores de industria, comercio y servicios.

\section{Salario mínimo}

El impacto del salario mínimo en el empleo ha sido muy debatido en la literatura y continúa siendo un tema altamente sensible y decisivo en la discusión sobre reforma laboral y pensional que reclaman los gremios, los organismos económicos internacionales y parte de la academia, para quienes es común sostener que el alto salario mínimo junto con sus incrementos anuales se constituye en las causantes principales del desempleo y la ocupación informal. No obstante, es importante mencionar que esa relación, como la magnitud de los impactos entre desempleo, salario mínimo y ocupación informal, no deja de ser teóricamente ambigua, y que la evidencia empírica no es concluyente, sino más bien controversial. En el país existe evidencia que controvierte el enfoque tradicional sobre la relación entre salario mínimo e informalidad (Rhenals, 2009). Al tiempo, se tienen otros estudios que exponen lo contrario, además de otros problemas asociados a esta relación.

En Colombia, se ha establecido que un incremento en el salario mínimo, si bien mejora las condiciones de vida de los hogares en la parte media y superior de la distribución del ingreso, no solo eleva la probabilidad de convertir a sus miembros en desempleado (Maloney \& Núñez, 2004), sino que genera pérdidas netas para los hogares de menores ingresos (Arango \& Pachón, 2004). En otras palabras, el incremento del salario mínimo en 
Colombia trae desempleo y para algunas ciudades es regresivo. Esto hace pensar que la desocupación y el empobrecimiento pueden actuar como eslabones del mecanismo de transmisión que alimenta la ocupación informal.

En la misma tradición de investigación, algunos estudios más recientes analizan la relación entre salario mínimo y la ocupación creada en la economía informal, encontrando que en Colombia el aumento de su nivel está altamente correlacionado con la rigidez del mercado laboral, en particular el salario mínimo y los costos no salariales, que representan en promedio el $58 \%$ del salario que recibe el trabajador. La consecuencia es que con costos no salariales y salario mínimo elevados, la economía formal se ajusta a los ciclos económicos a través de cantidades, perjudicando a los trabajadores poco calificados (Mondragón et al., 2010).

Al estudiar el mismo punto, Albrecht et al. (2008) encuentran que incrementos en los costos no salariales acrecientan la ocupación en la economía informal, especialmente en los trabajos por cuenta propia, generando una disminución en la productividad y en los salarios promedio de la economía. Este resultado coincide con lo encontrado por Santa-María et al. (2009), quienes sugieren que el alza de los costos no salariales aumenta no solo el desempleo sino también el número de trabajadores informales.

Por su parte, Arango y Flórez (2017) identificaron que la tasa de ocupación formal se afecta negativamente con el salario mínimo, es decir, hallaron un efecto positivo y estadísticamente significativo del salario mínimo sobre la tasa de informalidad, lo que presupone un impacto sobre el desempleo, expandiendo, al mismo tiempo, la economía informal; en particular, los ocupados por cuenta propia, que es el segmento más pobre. Vale mencionar que estos autores encuentran heterogeneidad regional de la ocupación informal y por tanto diferente productividad laboral entre ellas, razón por la cual proponen implementar un salario mínimo diferencial por regiones, lo que equivale a la recurrente formula de rebajar el salario mínimo a fin de crear más empleos en el sector formal.

En línea con lo anterior, pero con mayor inquietud, la Organización para la Cooperación y el Desarrollo Económicos (OCDE, 2019) recalca que el salario mínimo en Colombia, que es el más elevado de los países miembros, duplica el umbral de pobreza, contribuye a la informalidad y reduce las perspectivas laborales de los trabajadores con escasa cualificación, los jóvenes y las personas ubicadas en regiones menos desarrolladas (OECD, 2016). 
La solución de política preferida por la que se inclinan los estudios reseñados coincide con las recomendaciones de la OECD (2017), el Banco Mundial y el Fondo Monetario Internacional, que plantean como casi única solución la reducción del salario mínimo, puesto que al ser demasiado alto excluye del mercado laboral formal a los trabajadores menos productivos y de escasa calificación (Fedesarrollo, 2018), y por esta vía se contribuye a la desigualdad y a la pobreza en Colombia. En consecuencia, para disminuir la ocupación informal se justifica plenamente reducir el salario mínimo y fijarlo en estricta coherencia con los niveles de productividad laboral (Fedesarrollo, 2013). Frente a este aspecto vale recordar que esta fórmula es bastante cuestionada debido al complejo problema de baja productividad factorial que acusa a la economía colombiana. En el caso del trabajador, su exigua productividad laboral, en general, está vinculada con los pésimos desempeños en eficiencia del mercado laboral, a la poca preparación tecnológica y al escaso nivel educativo, variable fundamental para mejorar la productividad laboral y reducir la pobreza. Además, la productividad del capital en Colombia también es baja, aunque sus causas se asocian con serias fallas del mercado (acceso y falta de crédito, atraso en el sistema vial del país y altos costos del transporte), combinadas con problemas de manejo macroeconómico (Camacho \& Conover, 2010) (régimen tributario volátil y discriminatorio) y de políticas públicas (políticas de desarrollo productivo insuficientes o pobremente diseñadas) que entorpecen la profundización de la innovación empresarial, el incremento de la competitividad internacional y el crecimiento y la promoción de las empresas. La consecuencia de la baja productividad de los factores es que esta obstaculiza la formalización y deteriora los ingresos de los asalariados.

Finalmente, como se observa, si bien los estudios descritos y sus resultados pueden contener verdades, estas no dejan de ser deficientes, debido a que ignoran los factores históricos y estructurales del desarrollo de la economía. Por consiguiente, a partir de ellos no se puede concluir de manera simplista que el salario mínimo, sus incrementos y el impacto en el nivel de desempleo, característico del mercado laboral formal, son los factores últimos que explican la ocupación informal.

\section{El crecimiento económico}

Uno de los determinantes relevantes para entender la dinámica de la economía informal y la ocupación creada por ella es la tasa y el patrón del crecimiento económico. Esto último, reflejado en la dinámica del PIB, está 
relacionado con movimientos en la ocupación y el desempleo. Existe consenso en que el impacto directo de ese crecimiento sobre esas variables del mercado laboral afecta, por esta vía, el nivel de ocupación de la economía informal (OIT, 2002). En este sentido, aquellos países que experimentan exiguas tasas de crecimiento, así como aquellos que han impulsado el crecimiento industrial con base en el uso intensivo del factor capital, convergen en una situación de "crecimiento sin empleo" (jobless recovery). El fenómeno se ha registrado en EE. UU. desde la década de los noventa del siglo pasado (Bernanke, 2003; Groshen \& Porter, 2003; Lee \& Rudick, 2006) y posteriormente en México (Alcaraz \& García, 2006), Centro y Suramérica (Trapé, 2007), incluida Colombia (Pérez, 2007a). En EE. UU. el fenómeno ha sido de crecimiento económico con un lento aumento del empleo, mientras que en los países latinoamericanos se ha observado un crecimiento de las economías que crea muy poco empleo o en caso extremo no lo genera. Para estos últimos países, en ambos escenarios (uso intensivo del capital y bajas tasas de crecimiento de la economía) se crea desempleo debido a que no se generan las cantidades de puestos de trabajo necesarias para satisfacer toda la oferta laboral. En consecuencia, alguna cantidad de individuos que no pueden mantenerse en estado de desempleo, mediante la creación de un negocio propio como puesto de trabajo, pasan a ser unidades económicas de la economía informal, unas veces como cuenta propia y otras como empleadores.

En Colombia se han registrado ambos casos, e incluso una combinación de los dos. Sin embargo, lo recurrentemente característico es el crecimiento económico sin empleo originado, principalmente, en una combinación de factores de producción donde predomina una marcada intensidad de capital con detrimento del factor trabajo. Estudios compilados por Ocampo (2015) permiten concluir que esto último es una característica histórica de la industria manufacturera adquirida en el proceso de desarrollo industrial del país ocurrido entre 1945 y 1974. Para períodos recientes, Clavijo (2009) muestra evidencia de un uso creciente y significativo del factor capital desde 1990 hasta 2006, mientras que Clavijo y Fandiño (2015) confirman la misma tendencia en el período 2009-2015, lo cual explican por la constante caída del precio capital y al alza en el costo del trabajo, pues en ese período la utilización de factores en la relación capital/trabajo superó su tendencia de largo plazo, alcanzando un $63 \%$ en 2014. Otra evidencia importante de este hecho macroeconómico que ha restringido la ocupación de la fuerza 
laboral en el país la ofrece el sector manufacturero, donde la participación del trabajo ha registrado por décadas una tendencia decreciente, tanto así que su participación en la producción cayó de 12 \% en 1974 a 5 \% en 2012, al tiempo que la participación del capital en la producción pasó de $36 \%$ en 1974 a 40 \% en 2012 (Nieto, 2015).

De otro lado, pese a que actualmente no existe suficiente información en el país, es necesario tener presente que en los sectores de la economía colombiana que están experimentado crecimiento con base en la implementación de "tecnologías de punta", la demanda de trabajo altamente especializado desplaza a la mayoría de las personas no cualificadas a buscar ocupación dentro de la economía informal. Según Lesmes (2014), lo mismo empezó a suceder con las grandes empresas de los sectores económicos nuevos, que al momento de adoptar innovadoras herramientas tecnológicas y modelos de negocio empezaron a crear el mismo valor agregado con menos fuerza de trabajo.

En Colombia también hay evidencia de tasas de crecimiento del PIB insuficientes, que no alcanzan a reducir satisfactoriamente el desempleo urbano, la economía informal y la ocupación generada en ella. Efectivamente, entre 2001 y 2007, la economía colombiana tuvo períodos de crecimiento económico sobresalientes, aunque con tasas de desempleo en aumento y altas tasas de informalidad, en particular a partir del segundo trimestre de 2006 (Pérez, 2007b). En este aspecto, el antecedente más reciente es el crecimiento de $3 \%$ que registró el PIB en 2019 (frente al promedio latinoamericano de cerca de $1 \%$ ), pese a lo cual la economía nacional experimentó un desempleo creciente, con tasas superiores a los dos dígitos durante la mayoría de los meses de este año, siendo la segunda tasa más alta de América Latina, después de Brasil (OCDE, 2019), tendencia que se mantuvo 
en $2020 .{ }^{10}$ Por supuesto, todo esto acompañado una tasa urbana de informalidad del $51 \%$.

Estos hechos ilustran cómo una de las principales razones del incremento de la desocupación, que en cierta medida impacta la ocupación informal, es la tasa de crecimiento económico que no permite atender el aumento de la población en edad de trabajar y su presión sobre el mercado; es decir, el incremento de las personas que salen a buscar trabajo y las que no lo tienen. Por lo anterior, gremios como la Asociación Nacional de Empresarios de Colombia (ANDI), aunque ignoran la estrechez y poca capacidad de expansión de los mercados, consideran que el $\mathrm{PIB}^{11}$ debe crecer a tasas de 4 o 4,5\% a fin de contrarrestar esos problemas.

\section{La efectividad de la política económica}

De acuerdo con los preceptos económicos del neoliberalismo promovidos desde finales de la década de los 80 del siglo pasado por las entidades multilaterales prestamistas, en el país, las medidas de política económica más importantes para reducir la ocupación informal y el desempleo básicamente se han enfocado en la eliminación de los aportes parafiscales en nómina, junto con la implementación de políticas de administración del salario mínimo orientadas a la eliminación de su incremento gradual en términos reales $y$, por supuesto, medidas encauzadas a profundizar la flexibilización laboral. Como se comprueba en este trabajo, lo cierto es que en los últimos veinte años la efectividad de las medidas normativas y de política parecen no haber sido suficientemente efectivas para reducir la magnitud

10 El derrumbe de los precios del petróleo y la crisis pandémica por COVID-19, como en los demás países, ha paralizado la economía colombiana. Para 2020, el Banco de la República pronosticó una contracción del PIB cercana a 7 \%. Por su parte, el Ministerio de Hacienda estima que el endeudamiento nacional puede alcanzar el $63 \%$ como proporción del PIB, con sus correspondientes secuelas fiscales. Por otro lado, pese a que el desempleo venía subiendo desde el 2019, Fedesarrollo estimó una tasa cercana al $20 \%$ y un inevitable deterioro de los indicadores de pobreza. La crisis, el aislamiento social y la cuarentena decretada por el gobierno para enfrentarla también golpean a la economía informal, como lo prueba el éxodo de centenares de ciudadanos venezolanos que retornan a su país, quienes — ahora sin posibilidad algunasubsistían proveyéndose de trabajo e ingresos en el ámbito de la economía informal. Pero sobre todo, la inesperada crisis ha puesto al descubierto el drama de la pobreza y la vulnerabilidad alimentaria y de salud de estos trabajadores para sobrevivir a la pandemia y el alto riesgo que tienen de profundizar su miseria. El origen de la actual recesión económica es atípico y superarla probablemente será un lento proceso, especialmente la recuperación del empleo, dependiendo todo de la persistencia del choque pandémico en los siguientes años y la efectividad de las medidas de política monetaria y fiscal.

11 Aunque hay quienes piensan que en definitiva el problema de fondo en el país consiste en la coexistencia de un salario mínimo relativamente alto (con relación al salario medio o al PIB per cápita), con costos laborales igualmente altos, que genera tasas de desempleo e informalidad altas y persistentes, aún en presencia de un buen crecimiento económico Santa-María et al. (2009). 
de la ocupación creada por la economía informal, pues su disminución hasta hoy ha sido mínima y su nivel más bien continúa siendo muy elevado.

En efecto, con el objetivo explícito de generar empleo formal para trabajadores poco calificados, la Ley 789 de 2002, de flexibilización laboral, amplió el horario de la jornada laboral diurna de 6 a. m. hasta las 10 p. m., eliminó el pago de horas extras para todos los trabajadores que laboraran entre 6 p. m. y 10 p. m., redujo los pagos adicionales por trabajos en domingos y festivos y disminuyó los pagos de indemnización por despidos sin justa causa. Esta ley pretendía aumentar las ganancias de las empresas y así generar empleo a través de los recursos ahorrados, pero, al no hacer obligatorio ese propósito, ocurrió que las empresas beneficiarias aumentaron sus utilidades, el empleo formal no creció, los trabajadores vieron caer sus ingresos y la informalidad se mantuvo. La evidencia ha mostrado que esta reforma no tuvo efecto sobre la ocupación y la formalización del empleo (Gaviria, 2005).

En Colombia, las dos principales fallas del mercado laboral, manifiestas en el bajo nivel educativo de la mayoría de los trabajadores que segmenta el mercado y los costos por trabajador, han hecho que la afiliación al sistema de pensiones tenga muy baja cobertura, problema que en buena parte obedece a los altos niveles de ocupación dentro de la economía informal, al desempleo y a la inestabilidad del empleo asalariado en el sector formal. Para obtener mejoras sustanciales en cobertura y afiliación, apareció la Ley 797 de 2003, de reforma pensional. Sin embargo, ignorando que es común en los empresarios del país discriminar y excluir a los individuos por su edad, dicha ley, en detrimento de la formalización laboral, aumentó la edad de pensión y las semanas de cotización. Además, como no asignó incentivos para disminuir la carga impositiva sobre los sueldos de los trabajadores, esta ley también produjo efectos negativos para el pago de la cotización de pensión. Por consiguiente, la búsqueda de mayor cobertura y afiliación no se materializó de manera efectiva y menos aún se logró fortalecer el empleo formal.

A través de la Ley 1429 de 2010, de formalización y generación de empleo, más orientada a las empresas de empleadores informales, se buscó reducir la carga tributaria relacionada con la contratación de mano de obra formal. Sin embargo, esta al final terminó beneficiando a las empresas formales creadas antes de ella, y su objetivo de formalizar 500 mil empleos no resultó exitoso. Fueron pocas las empresas que se favorecieron de los descuentos tributarios, parte de los empleos creados fueron temporales 
(Pineda-Duque, 2015) y los trabajadores contratados apenas alcanzaron al $30 \%$ de lo que aspiraba el gobierno (Farné \& Rodríguez, 2013). En consecuencia, con esta ley la ocupación informal tampoco se vio afectada.

Para numerosos analistas, la expedición de la Ley 1607 de 2012, de reforma tributaria, ha sido la medida económica más efectiva para reducir la ocupación informal. Para promover el empleo formal, esta ley disminuyó los costos de contratación para las empresas, de forma que las contribuciones del empleador cayeron en 13,5 puntos porcentuales para el caso de los asalariados con ingresos de 1 a 10 salarios mínimos. Con esto, el impuesto total sobre el trabajo se redujo en $28,8 \%$, al pasar de 60,3 a $46,8 \%$. No obstante, la tasa de informalidad de los ocupados por cuenta propia apenas cayó de 93,7 \% en diciembre de 2011 a $92 \%$ a finales de 2016 (Garlati, 2019).

En este marco de resultados, la OCDE (2019) destaca los hallazgos de las evaluaciones de impacto realizadas (Bernal et al., 2017; Fernández \& Villar, 2016; Kugler et al., 2017; Morales \& Medina, 2016), las cuales sugieren que la disminución de los impuestos sobre la nómina indujo una reducción de entre 2 y 4 puntos porcentuales en la tasa de informalidad, con mayor efecto en los trabajadores asalariados que en los trabajadores por cuenta propia. Por su parte, el FMI sostiene que la mejoría en la formalidad laboral está en línea con la tendencia general de América Latina, donde el fuerte crecimiento del PIB y una dinámica favorable del mercado laboral han tenido un impacto positivo sobre la formalización del empleo (Cherif et al., 2018).

Sin embargo, pese a todos los esfuerzos por mejorar la formalización, la tozuda realidad muestra que la ocupación generada en la economía informal sigue siendo muy alta en el país. Aunque esta ocupación ha mostrado cierta disminución en los últimos años, alrededor del $60 \%$ del total de los trabajadores urbanos siguen trabajando en el ámbito de la economía informal (OCDE, 2019).

Pese al optimismo del FMI, los resultados de las medidas comentadas dejan ver su pobre efectividad para reducir significativamente la ocupación informal. La razón principal de tal ineficacia se encuentra en que las medidas económicas, de mediano y largo plazo, adoptadas por los formuladores de política para reducir la ocupación generada en la economía informal nunca se han enfocado para beneficiar el núcleo duro de este tipo de economía, es decir, a los ocupados por cuenta propia. Por el contrario, estas medidas han sido elaboradas para favorecer a las empresas que operan en la informalidad, más concretamente para favorecer propietarios de 
negocios informales (los patronos o empleadores), que son menos pobres y menos vulnerables que los ocupados informales por cuenta propia. Y no es que lo anterior esté mal, lo reprochable es que no se identifique el segmento crítico de la informalidad y se propongan políticas consecuentes. En este sentido, llama la atención que pese a los pobres resultados hasta ahora alcanzados, los formuladores de política no corrijan y continúen dándole prioridad a ese criterio de diseño. Por ejemplo, el documento CONPES 3956 de enero de 2019 (DNP, 2019), si bien se circunscribe a las políticas de formalización y desarrollo empresarial, no establece políticas ni recomendaciones para el núcleo duro de la ocupación informal, que representa alrededor del $90 \%$ de los ocupados en la economía informal. Sin duda, estos aspectos son relevantes para entender los insignificantes resultados de las medidas gubernamentales para formalizar a los empleadores informales y a los ocupados por cuenta propia.

Para concluir esta sección, cabe subrayar que reducir el nivel de la ocupación en la economía informal es una tarea de largo plazo que implica admitir que la economía colombiana carece de capacidad en el mediano plazo para incorporar al trabajo decente a cerca de ocho millones de ocupados que operan allí, y que, adicionalmente, se trata de un problema ligado a la erradicación de la pobreza extrema, ${ }^{12}$ la falta de oportunidades, entrenamiento y de educación (especialmente) y, más allá, a la desigualdad y la concentración del ingreso y la riqueza. Para reducir eficientemente la economía informal y la ocupación generada en ella, es necesario implementar un programa con una estrategia integral de largo plazo dirigida al núcleo duro de la informalidad que, sobre todo, trascienda las políticas de flexibilización laboral. Sin duda, un programa así impone el diseño de estrategias y políticas económicas y sociales que tengan como centro el empleo productivo para toda la población, la erradicación de la miseria y la reducción substancial pobreza, el acceso a la seguridad social y a la educación de alta calidad, junto con políticas públicas que contribuyan a la ampliación y diversificación del mercado externo e interno, respaldadas fiscalmente con un régimen tributario progresista que estimule y comprometa al empresariado y a los trabajadores. De otra forma, las medidas, como hasta ahora, continuaran teniendo débiles resultados. 


\section{Principales causas estructurales e históricas de la ocupación informal}

Si bien es cierto que la tasa de crecimiento de la economía colombiana, que en lo corrido del presente siglo ha mostrado poco vigor para crear empleo formal, es un factor importante que alienta la ocupación en la economía informal y el desempleo en el país, tampoco se puede continuar ignorando que ambos hechos se encuentran ligados, por lo menos, con otros dos factores históricos y estructurales distintivos del desarrollo de la economía, que se combinan y son de importancia en cualquier consideración. El primero, de tipo estructural, es la falta de capacidad de la economía en su conjunto para absorber, por lo menos, un alto porcentaje de la fuerza de trabajo (Kalmanovitz, 2015). El segundo, que tal incapacidad de absorción es un problema relacionado con el patrón histórico que se fue configurando con el lento y tortuoso desarrollo del capitalismo colombiano (Bértola \& Ocampo, 2016; Kalmanovitz, 1983; Sunkel \& Paz, 1982; Tovar, 1984).

En cuanto el primer factor, se trata de una restricción que en parte tiene que ver con el tamaño del mercado interno nacional, el cual históricamente ha sido una de las importantes condiciones internas necesarias para estimular la ampliación y el desarrollo de los sectores económicos, pero especialmente de la industria. Para los países de la región, la naturaleza, dimensión y capacidad del mercado interno se derivan de la formación histórica experimentada por las economías en sus etapas previas del desarrollo. En este sentido, ese proceso en Colombia, como se sabe, ha estado acompañado de una desigualdad extrema de la distribución del ingreso, hecho que, a lo largo de la historia, ha limitado la formación de mercados de bienes y servicios amplios y masivos, generadores de empleo formal. En consecuencia, frente a lo que se puede ver en países de otras latitudes, el país actual carece de un mercado interno y externo grande, diversificado, innovador y dinámico, abastecido por empresas altamente productivas y competitivas. Esta carencia se complejizó todavía más a raíz del proceso de globalización y liberalización que empezó a experimentar la economía colombiana desde mediados de los años setenta hasta el final del siglo XX y que la sumió en un proceso de desindustrialización, originado en el desmonte y reducción de aranceles (1978-1982), la liberación financiera (1974-1978) y la subsiguiente 
apertura comercial iniciada en $1991,^{13}$ fenómeno que se acentuó con la expansión de la actividad minero-energética centrada en la producción de carbón y petróleo. Como consecuencia, en las primeras décadas del presente siglo se consolidó un proceso de desindustrializada y reprimarización en la economía colombiana. En este contexto, las tasas de crecimiento global de su producción son insuficientes para ocupar la oferta de trabajo de la población, con lo cual se mantiene un alto número de desempleados y de población marginal que nutren la economía informal. El escenario actual del país sugiere que es justamente el nivel de desarrollo estructural de la economía y su retroceso uno de los principales determinantes de la dimensión y persistencia de la economía informal y la ocupación derivada de esta.

Con relación al segundo factor, es importante señalar que los principales estudios indican que en los países latinoamericanos con más desarrollo el proceso de industrialización, ocurrido desde la primera guerra mundial hasta el final de su vigencia, no fue, como se esperaba, un significativo generador de ocupaciones debido a que dicho proceso se realizó a través de la utilización creciente de tecnología cada vez más intensiva en capital. De esta manera, la utilización de mano de obra se hizo decreciente y en todos los países se empezó a conformar una masa de "marginados" apartados transitoria o definitivamente de la economía formal. En este contexto regional, en Colombia, durante el período transcurrido desde mediados de la segunda década del siglo XX hasta el agotamiento del proceso de sustitución de importaciones en 1974 (o industrialización orientada por el Estado), se registraron importantes avances en el desarrollo y modernización de la economía, todo esto fortalecido por el éxodo rural, el crecimiento demográfico y el proceso de urbanización. Sin embargo, concluido este período de desarrollo, el país entró en uno nuevo de globalización y apertura comercial de la economía, el cual condujo, desde los años noventa del siglo pasado y hasta hoy, a la desindustrialización y reprimarización de la economía. En estos dos períodos históricos del desarrollo económico del país se fue gestando y consolidando un contingente de masa popular de baja calificación laboral sin posibilidades de acceso a la economía formal, que como se ha visto hoy tienen gran peso en la economía nacional, particularmente en materia de

13 Después de tres décadas del CONPES 2465 de 1991, de apertura de la economía, la producción de las industrias manufactureras y las actividades agrícolas, ganaderas, de caza, silvicultura y pesca, redujeron notablemente su participación en el PIB, perdiendo, respectivamente, 7,5 y 11 puntos porcentuales. 
ocupación, que, entre otras, ha sido el aspecto más estudiado frente al de su producción de bienes y servicios.

\section{INFORMACIÓN ESTADÍSTICA}

De acuerdo con las clasificaciones del $\mathrm{DANE},{ }^{14}$ el dominio de análisis de esta investigación corresponde al ámbito urbano o cabecera municipal; es decir, el área rural, o centro poblado, y el rural disperso fueron excluidos. Puesto que el área urbana envuelve un tejido económico y social continuo más amplio que el de las trece ciudades y áreas metropolitanas del país, el nivel de las variables de estudio es superior al observado en las trece grandes ciudades. En este orden, la información utilizada aquí incorpora la ocupación originada en la economía informal, mientras que del lado de la economía formal incluye el desempleo urbano, el salario mínimo real, el empleo formal en las actividades de manufactura, comercio y servicios $y$, adicionalmente, el Producto Interno Bruto real.

En el sistema de ecuaciones objeto de análisis la principal variable de estudio es la ocupación por cuenta propia generada en la economía informal, que incluye trabajadores domésticos, trabajadores familiares sin remuneración, trabajadores sin remuneración ocupados en otros hogares y jornaleros y peones. De acuerdo con lo establecido en la sección anterior, el salario mínimo real es una información fundamental para el modelo porque es proxi de los costos laborales y referente que marca la pauta para el crecimiento del resto de salarios de la economía (Bonilla, 2011). Adicionalmente, este tiene cierta incidencia en el desempleo urbano de la economía formal, afectando secundariamente, por esta vía, el nivel de ocupación de la economía informal. Por su parte, la información del empleo formal creado en industria, comercio y servicios se tiene en cuenta a fin de establecer el impacto que sus movimientos ejercen sobre la ocupación creada en la economía informal, principalmente en el comercio y la industria. Por último, el sistema de ecuaciones incluye el PIB real como variable que contribuye a captar los efectos del crecimiento económico sobre la ocupación en la economía informal y en el mercado laboral formal.

14 Los dominios de estudio se refieren a los definidos en las metodologías de las investigaciones estadísticas realizadas por el DANE, la ECV y la GEIH. 
Todas las variables se encuentran en logaritmos naturales, corresponden a datos trimestrales y comprenden el período 2001.I - 2019. IV. Del DANE (www.dane.gov.co) se obtuvo la información básica de las series de desempleo, informalidad, empleo y PIB, mientras que la información de salario mínimo y su deflactor, el índice de precios al consumidor, se tomó del Banco de la República (www.banrep.gov.co).

\section{EL MODELO VECTORIAL DE CORRECCIÓN DE ERRORES (MVCE)}

La ocupación generada en la economía informal y un elevado índice de desempleo, íntimamente vinculados a la debilidad estructural, manifiesta en el desarrollo desigual intra e intersectorial de la economía formal, por décadas han hecho parte de los problemas de primer orden que afectan a la economía colombiana. En materia de elaboración y evaluación de políticas económicas para erradicar esas dificultades y sus secuelas sociales y económicas, es de gran importancia conocer y analizar los movimientos y las respuestas que se registran entre la ocupación en la economía informal, las variables claves del mercado laboral formal colombiano y el PIB. Con este fin, en la presente sección se evalúa empíricamente la taxonomía jerárquica de esas variables, determinada por la fuerza de su respuesta, para explicar la variabilidad y los movimientos experimentados en la ocupación causada en la economía informal. A través de un modelo vectorial de corrección de errores (MVCE), y mediante el análisis de las funciones impulso-respuesta y el procedimiento de descomposición de varianza de las variables del sistema, se examina si entre estas existen relaciones de equilibrio de largo plazo y con qué intensidad responden cada una de ellas ante choques estocásticos que puedan experimentar.

El sistema de ecuaciones conformado por las variables de estudio involucra combinaciones lineales estacionarias de variables no estacionarias. Así, el empleo de un MVCE permite evaluar rigurosamente un sistema como el descrito, en el cual aunque las variables no son estacionarias sí tienen el mismo orden de integración (generalmente I [1]), y su combinación lineal (sus residuales) es estacionaria. Se trata de un sistema de ecuaciones cointegrado, en el cual es un serio error diferenciar las variables que lo conforman debido a la pérdida de información que trae consigo la diferenciación, pues en este evento, si bien se obtiene un sistema VAR estacionario y es legítimo 
emplear la metodología Box-Jenkins para el análisis del sistema, se incurre en el error de sesgo de variable omitida o de regresión espuria (Granger \& Newbold, 1974), inhabilitando así la inferencia estadística.

Lo relevante es que las variables cointegradas tienen una representación de corrección de error, lo que significa que la dinámica de corto plazo de las variables del sistema está influenciada por la desviación de equilibrio de largo plazo. Por ello, para que el sistema vuelva a ese equilibrio, los movimientos de al menos algunas de las variables deben responder a la magnitud del desequilibrio. En este sentido, el modelo para el análisis de la ocupación en el ámbito de la economía informal implica investigar la existencia de esas relaciones de cointegración y encontrar el término de corrección de error para establecer finalmente, así, qué tan influyentes son las innovaciones que experimentan el salario mínimo, el desempleo urbano, el empleo en los sectores de manufactura y comercio y la producción económica general para explicar la varianza de la ocupación informal.

\section{Modelo general}

El modelo econométrico que explica la ocupación ocasionada en la Economía Informal en función del salario mínimo (Smr), el desempleo urbano (Dsu), el empleo los sectores manufactura (Efm), comercio (Ecm) y el $\mathrm{PIBr}$, se expresa como:

$$
O c i f=\beta_{o}+@ t+\beta_{1} D s u+\beta_{2} S m r+\beta_{3} E m f+\beta_{4} E c m+\beta_{5} P I B r+\varepsilon_{t}(\text { Ec. 1) }
$$

La ecuación (1) permite estimar la relación de equilibrio de largo plazo entre las variables del sistema. En cuanto al signo de los coeficientes, se supone una relación positiva entre ocupación en la economía informal (Ocif) y el desempleo urbano (Dsu). Así mismo, como se vio en la sección de revisión de la literatura, existe una relación directa y positiva entre el nivel de ocupación informal y el salario mínimo (Smr). Igualmente, se supone que el empleo generado en los sectores de manufactura (Emf) y comercio (Ecm) impactan negativamente los niveles de ocupación producidos en la economía informal. Por último, aunque teóricamente se espera que el crecimiento del producto interno bruto contrarreste la economía informal y ende, la ocupación originada en ella, de acuerdo con la evidencia del crecimiento sin empleo (y por esta vía más ocupación informal), es conveniente probar si efectivamente el efecto del $\mathrm{PIBr}$ sobre la ocupación informal es positivo o no. De acuerdo con lo anterior, las restricciones de signo de los coeficientes de la relación de equilibro de largo plazo serían: 


$$
\beta_{1}>0 ; \beta_{2}>0 ; \beta_{3}=\beta_{4}<0, \beta_{5}=1 \text { (Ec. 2) }
$$

Según la ecuación (1), el vector de variables $x_{t}$ del sistema es:

$$
x=(\text { Ocif }, 1, D s u, S m r, E m f, E c m, \text { pibr })(\text { Ec. 3) }
$$

y su vector cointegrante $\beta$ :

$$
\beta=\left(1,-\beta_{1}-\beta_{2}-\beta_{3}-\beta_{4}-\beta_{5}\right)(\text { Ec. } 4)
$$

Si las variables del modelo son I (1) y la combinación lineal de (1) es estacionaria, se tiene que:

$$
\varepsilon_{t}=\text { Ocif }-\beta_{0}-\beta_{1} D s r-\beta_{2} S m r-\beta_{3} E m f-\beta_{4} E c m-\beta_{5} P I B r \text { (Ec. 5) }
$$

Luego las variables son cointegradas de orden $(1,1)$. De esta forma, la desviación de equilibrio de largo plazo (o error de equilibrio) está dado por:

$$
\varepsilon_{t}=\beta X_{t}
$$

que es estacionaria, es decir, carece de tendencia, por lo cual la deviación es de naturaleza temporal. Recuérdese que en el largo plazo $\varepsilon_{t}=0$.

\section{Especificación del modelo MVCE}

Una vez endogenizadas las variables del modelo general (1), formalmente el MVCE estimado es un sistema conformado por el término de corrección de error y por un número de ecuaciones diferenciadas de primer orden, donde todas las variables son endógenas y son regresadas contra $p$ términos de sus propios valores rezagados. Su importancia consiste en que permiten identificar las relaciones de equilibrio de largo plazo, las dinámicas de corto plazo y los impactos de perturbaciones aleatorias que experimente el sistema de variables. De manera compacta, el sistema de ecuaciones que conforman el MVEC tiene la siguiente expresión:

$$
\Delta \mathrm{y}_{i t}=\pi_{i} y_{i t-l}+\sum_{j=I}^{p-1} \pi \Delta y_{i t-1}+\delta_{k} z_{i t}+\varepsilon_{i t} \text { (Ec. 6) }
$$

Donde $i=1,2,3,4,5,6 ; j=1,2,3,4,5,6 ; y k=1,2,3,4,5,6 ; \Delta$ es el operador de diferencia, $\pi_{i}$ y $\pi_{j}$ son matrices $6 \times 6$ de coeficientes que miden el efecto rezagado de corto y largo plazo de las variables entre sí; $\varepsilon_{i t}$ es el término de error y $\varepsilon_{i t} \sim i d d\left(0, \sigma^{2}\right) ; y_{i t}$ es el vector de $\mathrm{n}$ variables endógenas observables empleadas para explicar el respectivo modelo; $\mathrm{y} z_{i t}$ es un vector de variables exógenas. Una expresión equivalente del término de corrección de error es:

$$
\alpha \beta^{\prime}=\pi_{i} \text { (Ec. 7) }
$$

Por lo tanto, la ecuación (6) es equivalente a:

$$
\Delta y_{i t}=\alpha \beta^{\prime} y_{i t-I}+\sum_{j=I}^{p-1} \pi \Delta y_{i t-I}+\delta_{k} z_{i t}+\varepsilon_{i t} \text { (Ec. 8) }
$$


Donde $\alpha$ es el parámetro de velocidad de ajuste hacia el equilibrio.

Para una explicación más detallada, la ecuación (8) se puede expresar matricialmente como:

$$
\left[\begin{array}{l}
\Delta O c i f \\
\Delta D s u \\
\Delta S m r \\
\Delta E m f \\
\Delta E c m \\
\Delta P i b r
\end{array}\right]=\left[\begin{array}{l}
\alpha_{1} \\
\alpha_{2} \\
\alpha_{3} \\
\alpha_{4} \\
\alpha_{5} \\
\alpha_{6}
\end{array}\right]\left[\beta_{1} \beta_{2} \beta_{3} \beta_{4} \beta_{5} \beta_{6}\right]\left[\begin{array}{l}
O c i f_{t-1} \\
D s u_{t-1} \\
S m r_{t-1} \\
E m f_{t-1} \\
E c m_{t-1} \\
P i b r_{t-1}
\end{array}\right]+\pi_{1}\left[\begin{array}{l}
\Delta O c i f_{t-1} \\
\Delta D s u_{t-1} \\
\Delta S m r_{t-1} \\
\Delta E m f_{t-1} \\
\Delta E c m_{t-1} \\
\Delta P i b r_{t-1}
\end{array}\right]+\cdots+\pi_{4}\left[\begin{array}{l}
\Delta O c i f_{t-4} \\
\Delta D s u_{t-4} \\
\Delta S m r_{t-4} \\
\Delta E m f_{t-4} \\
\Delta E c m_{t-4} \\
\Delta P i b r_{t-4}
\end{array}\right]+\left[\begin{array}{l}
\delta_{1} \\
\delta_{2} \\
\delta_{3} \\
\delta_{4} \\
\delta_{5} \\
\delta_{6}
\end{array}\right] z_{i t}+\left[\begin{array}{l}
\varepsilon_{1 t} \\
\varepsilon_{2 t} \\
\varepsilon_{3 t} \\
\varepsilon_{4 t} \\
\varepsilon_{5 t} \\
\varepsilon_{6 t}
\end{array}\right]
$$

La parte izquierda del modelo es el vector de variables del sistema en primeras diferencias, es decir, el cambio en las variables en función de todos los elementos del lado derecho.

Por su lado, la primera parte del lado derecho está compuesta por cuatro términos. El primero es el término de corrección de errores $\left(\alpha \beta^{\prime} y_{i t-1}\right)$, cuya función es corregir los desequilibrios de corto plazo que se registren entre las variables del sistema, con lo cual se garantiza en el largo plazo que la combinación lineal $\left(\varepsilon_{i t}\right)$ entre el vector de cointegración y las variables sea estacionaria; es decir, que carezca de tendencia. Lo importante aquí es observar que en un MVCE la dinámica de las variables del sistema en el corto plazo está influenciada por las desviaciones del equilibrio de largo plazo. En efecto, se puede ver que los cambios en las variables del sistema responden a las desviaciones previas del equilibrio de largo plazo. La combinación lineal entre el vector cointegrante $\beta$ y el vector de variables rezagadas en un período debe ser igual a cero $\left(\beta x_{t}=0\right)$, lo cual ocurre cuando el sistema descrito está en equilibrio en el largo plazo. Cuando se presentan desviaciones en ese equilibrio (error de equilibrio, $\varepsilon_{i t}$ ) la combinación lineal es $\beta x_{t}=\varepsilon_{t}$ y la dinámica de las variables en el corto plazo se ve afectada y se va ajustando para converger al equilibrio. Aunque no se muestra, el MVCE estimado incorporó la constante y la variable de tiempo con el fin de capturar los efectos de una tendencia creciente y sostenida en las variables (anexo 4).

Respecto al vector de parámetros de velocidad de ajuste hacia el equilibrio $(\alpha)$, de dimensión $6 \times 1$, es de especial interés por la importante influencia que tiene sobre la dinámica del sistema. La función de cada valor del vector $\alpha_{i}$ es medir el grado y la rapidez con que responde la variable $i$ en cuestión a las desviaciones de equilibrio de largo plazo. Es claro que la dirección del cambio en las variables viene determinada por el signo de los coeficientes de velocidad. Así mismo, se puede ver que el mecanismo de 
transmisión del ajuste se da a través de la multiplicación del coeficiente $\alpha_{i}$ por la desviación de equilibrio de corto plazo, trasfiriendo así ese ajuste a cada variable del sistema, de tal forma que los cambios en las variables para el siguiente período dependerán del propio desequilibrio que registre en el período anterior.

La segunda parte del lado derecho del modelo muestra que los cambios en las variables del sistema también están influenciados por los cambios experimentados por todas variables en períodos anteriores, es decir, corresponden a la parte VAR en diferencias que, en este caso, es de orden cuatro. La tercera parte es un vector de variables exógenas ${ }^{15}$ introducida para el ajuste del modelo sin fines analíticos. La última parte es el vector de errores del modelo VEC, cuyo comportamiento se asume ruido blanco, es decir, de media cero y varianza constante, e implica que los cambios de las variables en el sistema también responden a los choques estocásticos (representados por $\varepsilon_{i t}$ ).

\section{RESULTADOS}

\section{Evaluación del orden de integración de las variables}

El examen gráfico de las variables del sistema permite ver que tienen movimientos crecientes y conjuntos, con lo que inicialmente se puede concluir que las series tienen raíces unitarias, es decir, son procesos no estacionarios I (1). Por lo tanto, se espera que las series estén cointegradas, es decir, que exista entre todas ellas relaciones de equilibrio de largo plazo (figura 1).
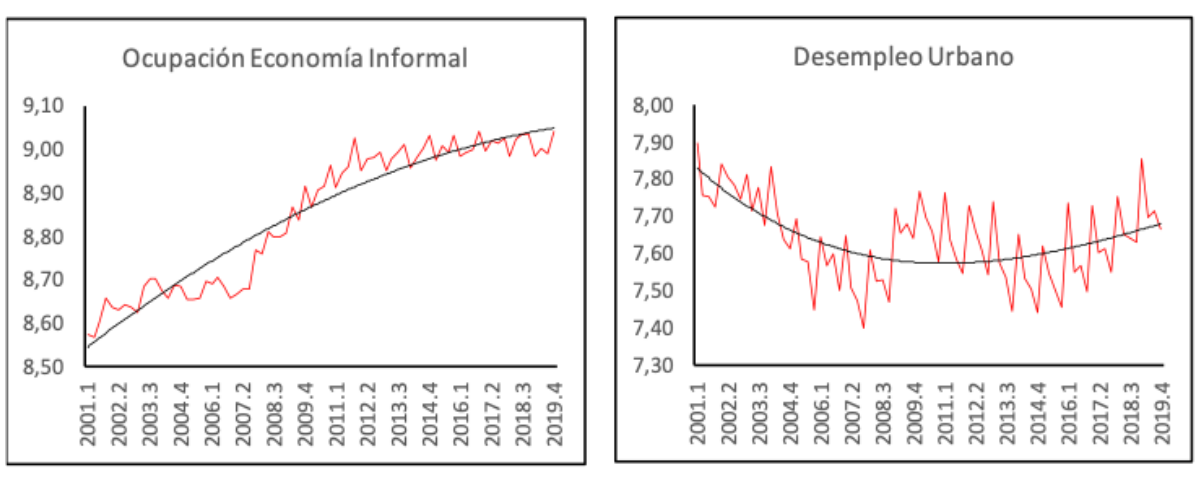

Figura 1. Ocupación en la economía informal, desempleo urbano, salario mínimo, empleo en manufactura y comercio y $\mathrm{PBI}$ (2001.I-2019.IV)

15 En el MVCE inicial se incluyó el empleo en sector de servicios. Sin embargo, debido a la alta colinealidad que presenta con respecto al empleo en el sector de la manufactura, a su baja significancia estadística y a la distorsión que ocasiona sobre los residuos del modelo, se excluyó y se dejó como una variable exógena con fines de ajuste del modelo y sin propósitos analíticos. 

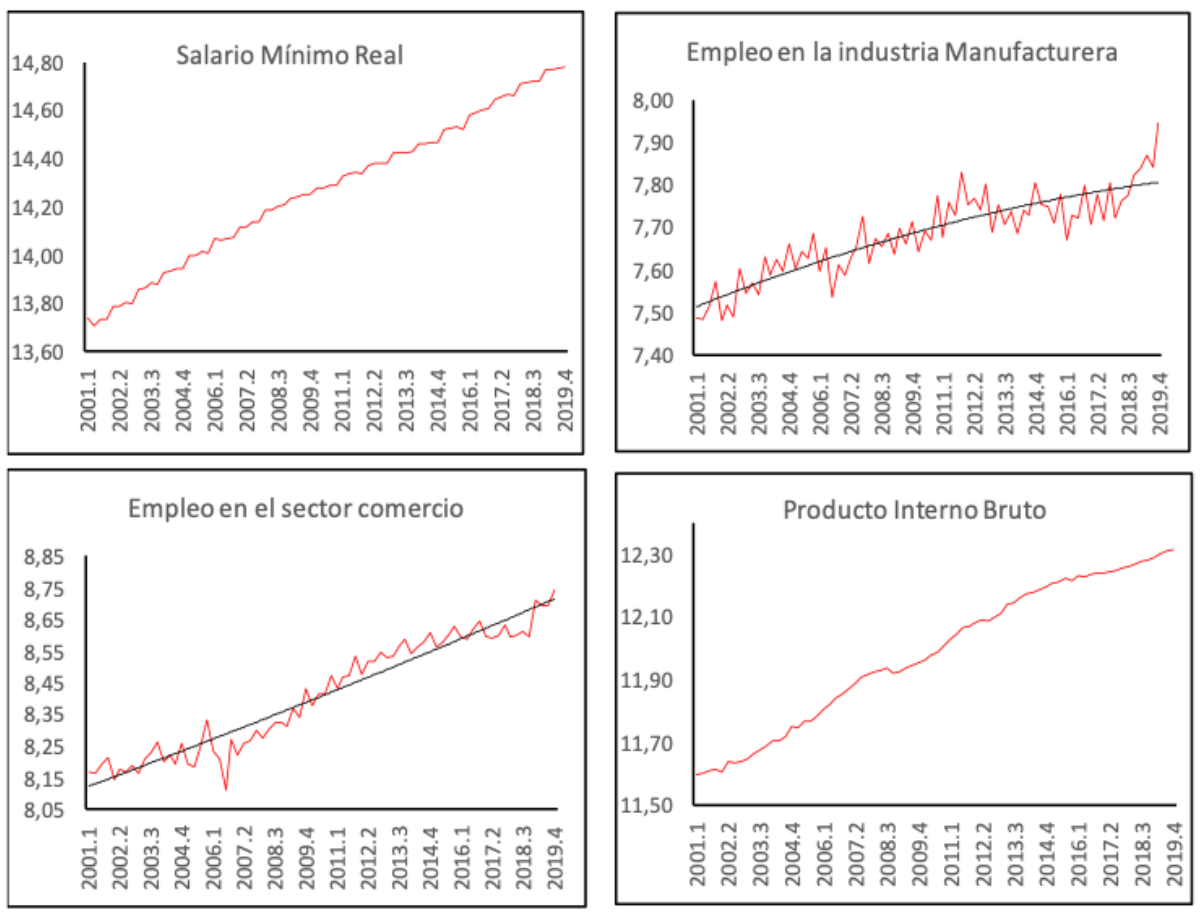

\section{Pruebas de raíces unitarias}

Según los supuestos básicos del modelo clásico de regresión, un sistema de ecuaciones con variables no estacionarias se puede diferenciar para transformarlo en un sistema estacionario y efectuar el análisis mediante un modelo de vectores autorregresivos (VAR). Sin embargo, como ya se aclaró, este procedimiento es incorrecto cuando se está en presencia de un sistema con variables no estacionarias y cointegradas, ya que se pierde valiosa información de las variables contenidas en la desviación del equilibrio de largo plazo, conocida como error de equilibrio ( $\varepsilon t)$, y por lo tanto se incurre en un sesgo de variable omitida o regresión espuria invalidando las estimaciones y toda la inferencia econométrica derivada (Enders, 2004).

En un complejo contexto multivariado de variables económicas como las mencionadas aquí, el sesgo de variable omitida se evita empleando un MVCE que tiene como condición primera que las variables sean no estacionarias. En este sentido, la exploración gráfica de las variables objeto de estudio reveló que las series tienen tendencia y en potencia son procesos I (1). La metodología formal para concluir si las series cumplen con la condición de estacionariedad es la prueba de Dickey-Fuller ampliada, la cual se aplica a las variables en nivel y a la primera y segunda diferencia, y cuya hipótesis nula $\left(\mathrm{H}_{0}\right)$ dice que la variable en cuestión tiene una raíz unitaria. 
De acuerdo con lo anterior, los resultados de la prueba para las series en niveles se presentan en la tabla 3. Para todas las variables se incluyó en la ecuación de prueba la constante y el término de tendencia, y de acuerdo con los resultados del criterio de información de Schwarz, se incluyen once rezagos. Además, se constató en los resultados de las regresiones de la ecuación de la prueba ADF la no presencia de correlación serial en los residuos, fijando como aceptable un Durbin-Watson entre 1,8 y 2,2.

\begin{tabular}{lcccccc}
\hline Variable & $\begin{array}{c}\text { Intercepto } \\
\text { tendencia }\end{array}$ & Rezagos & $\mathrm{t}_{\mathrm{ADF}}$ & $\mathrm{t}_{\text {critico al } 10 \%}$ & $\mathrm{P}_{\text {valor }}$ & $\mathrm{Se} \mathrm{rechaza} \mathrm{H}_{0}$ al $10 \%$ \\
\hline OCIF & $\mathrm{Si}$ & 6 & $-1,0410$ & $-3,1634$ & 0.9308 & No \\
$\mathrm{DSU}$ & $\mathrm{Si}$ & 3 & $-0,4458$ & $-3,1634$ & 0.9839 & No \\
$\mathrm{SMR}$ & $\mathrm{Si}$ & 4 & $-2,7499$ & $-3,1653$ & 0,2206 & No \\
$\mathrm{EMF}$ & $\mathrm{Si}$ & 6 & $-3,1467$ & $-3,1656$ & 0.1041 & No \\
$\mathrm{ECM}$ & $\mathrm{Si}$ & 3 & $-2,0412$ & $-3,1639$ & 0.5690 & No \\
$\mathrm{PIBr}$ & $\mathrm{Si}$ & 0 & $-0,5873$ & $-3,1624$ & 0.9768 & No \\
\hline
\end{tabular}

Tabla 3. Pruebas de raíz unitaria, series en niveles. Prueba de Dickey-Fuller Aumentada

Fuente: elaboración propia con datos del anexo 1.

Como se aprecia, para todas las series la respectiva prueba ADF cae dentro de la zona de no rechazo de la hipótesis nula. Por lo tanto, con un valor crítico del 0,1 no se puede rechazar la hipótesis nula de raíz unitaria para las series, es decir, son series I (1), lo cual es consistente con los resultados $p$-valor, marcadamente superiores a los niveles convencionales de significancia. Por ejemplo, para el caso de la ocupación causada dentro de la economía informal (Ocif), el estadístico $t_{A D F}$ de -1.0410 , con un $p$-valor de 0,9308 , al encontrarse dentro de la zona de no rechazo de la hipótesis nula, permite concluir que esta variable tiene una raíz unitaria y es no estacionaria.

Los resultados de la prueba a las series en primeras diferencias se muestran en la tabla 4. Como se observa, exceptuando el desempleo urbano (Dsu) y salario mínimo real (Smr), dados los $p$-valor en todas las series en primeras diferencias, se rechaza la hipótesis nula de raíz unitaria a un nivel de significancia del 0,01. Además, para todas las series, sin excepción, se rechaza la hipótesis al nivel de significancia del 0,05; es decir, las series en primeras diferencias son estacionarias.

En la sección precedente las pruebas de raíz unitaria para el análisis de integración mostraron que las series son procesos I (1). Por consiguiente, se puede implementar la prueba de cointegración para examinar si la combinación lineal del grupo de variables del sistema objeto de estudio cumple 
con la condición de ser estacionaria, es decir, debe tener media cero y varianza y covarianza constante.

Tabla 4. Pruebas de raíz unitaria, series en primeras diferencias. Prueba de Dickey-Fuller Aumentada

Fuente: elaboración propia con datos del anexo 1.

\begin{tabular}{ccccccc}
\hline \multirow{2}{*}{ Variable } & $\begin{array}{c}\text { Intercepto } \\
\text { y tendencia }\end{array}$ & Rezagos & \multicolumn{2}{c}{$\mathrm{t}_{\mathrm{ADF}}$} & $\mathrm{P}_{\text {valor }}$ & \multicolumn{2}{c}{ Rechazar } \\
\hline$\Delta \mathrm{OCIF}$ & $\mathrm{Si}$ & 6 & $-3,5057$ & 0.0000 & $\mathrm{Hi}$ & $\mathrm{Si}$ \\
$\Delta \mathrm{DSU}$ & $\mathrm{Si}$ & 3 & $-3,7535$ & 0.0250 & $\mathrm{No}$ & $\mathrm{Si}$ \\
$\Delta \mathrm{SMR}$ & $\mathrm{Si}$ & 4 & $-3,5599$ & 0,0407 & $\mathrm{No}$ & $\mathrm{Si}$ \\
$\Delta \mathrm{EMF}$ & $\mathrm{Si}$ & 6 & $-4,4041$ & 0.0041 & $\mathrm{Si}$ & $\mathrm{Si}$ \\
$\Delta \mathrm{ECM}$ & $\mathrm{Si}$ & 2 & $-9,4058$ & 0.0000 & $\mathrm{Si}$ & $\mathrm{Si}$ \\
$\Delta \mathrm{PIBr}$ & $\mathrm{Si}$ & 0 & $-9,4935$ & 0.0000 & $\mathrm{Si}$ & $\mathrm{Si}$ \\
\hline
\end{tabular}

\section{Prueba y resultados de cointegración de Johansen}

La prueba de Johansen, de amplio reconocimiento y de más utilización en la práctica, tiene el doble propósito de determinar el número r de relaciones de cointegración y probar las propiedades del vector de cointegración $\beta$ y de la matriz de coeficientes de velocidad de ajuste $(\alpha)$, siendo esto último una de las ventajas más importantes de esta prueba (Neusser, 2016). La ecuación cointegrante (o de equilibrio) empleada para efectuar la prueba de Johansen se denomina relación de equilibrio de largo plazo y permite modelar la convergencia de la dinámica de corto plazo hacia el equilibrio de largo plazo.

En el modelo estimado en este trabajo (Ec. 6), el procedimiento de Johansen identifica la relación cointegrante del sistema con base en que el rango ( $r$ ) de la matriz $\pi_{i^{\prime}}$ que contiene las desviaciones de largo plazo de las variables, es igual al número de vectores cointegrantes independientes. Si el rango es igual a r, rango $\left(\pi_{i}\right)=r$, entonces se pueden se presentan cuatro casos: i) si $\pi_{i}=0$, entonces se tiene una matriz nula, denotando que no existe ninguna relación de cointegración y lo que se tiene es un modelo VAR en primeras diferencias; ii) en el caso extremo cuando $\pi_{i}$ es de rango pleno, es decir rango $\left(\pi_{i}\right)=n$, el vector $y_{t}$ es un proceso estacionario ${ }^{16}$ y las variables no están cointegradas, puesto que todas son estacionarias; iii) en el caso intermedio, donde rango $\left(\pi_{i}\right)=1$, existe un vector cointegrante y la expresión $\pi_{i} y_{i t-1}$ es el término de corrección de error; iv) para los casos en que $1<$ rango $\left(\pi_{i}\right)<0$, existen múltiples vectores cointegrantes.

16 Enders afirma que, en este caso, cada una de las n variables contenidas en el vector xt pueden ser
estacionarias con valores de largo plazo dados por el vector cointegrante (Applied Econometric Time Series, capítulo 6, p. 335). 
Puesto que el rango de una matriz es igual al número de sus raíces característica distintas de cero, el número de los diferentes vectores cointegrantes se obtienen examinando la significancia de los eigenvalores de la matriz $\pi_{i^{\prime}}$ a través de los siguientes estadísticos propuestos por Johansen:

$$
\begin{gathered}
\lambda_{\text {trace }}(r)=-T \sum_{i=r+1}^{n} \ln \left(1-\hat{\lambda}_{i}\right) \\
\lambda_{\max }(r, r+1)=-T \ln \left(1-\hat{\lambda}_{r+1}\right)
\end{gathered}
$$

Donde $\lambda_{i}$ son los valores estimados de las raíces características obtenidos de la matriz $\pi_{i}$; - $T$ es el número de observaciones empleadas, 74 en este caso; y $\mathrm{n}$ el número de variables endógenas. El estadístico $\left(\lambda_{\text {trace }}\right)$ prueba la hipótesis nula que afirma que el número de distintos vectores cointegrantes es menor o igual a $r$ contra una alternativa general, es claro que $\lambda_{\text {trace }}=0$ cuando $\lambda_{i}=0$. El estadístico $\lambda_{\max }$ prueba la hipótesis nula que indica que el número de vectores cointegrantes es $r$ contra la alternativa de $r+1$ vectores

\begin{tabular}{|c|c|c|c|c|c|}
\hline \multicolumn{2}{|c|}{ Hipótesis } & \multirow{2}{*}{ Eigenvalor } & \multirow{2}{*}{$\lambda_{\text {trace }}$ Valor } & \multirow{2}{*}{$\begin{array}{c}\text { Valor crítico al } \\
0.05\end{array}$} & \multirow{2}{*}{$\mathrm{P}_{\text {valor }} * *$} \\
\hline $\mathrm{H}_{0}$ & $\mathrm{H}_{1}$ & & & & \\
\hline \multicolumn{6}{|c|}{ Test de la Traza para el rango de cointegración } \\
\hline \multicolumn{6}{|l|}{$\lambda_{\text {trace }}$ test } \\
\hline $\mathrm{r}=0^{*}$ & $r>0$ & 0.528904 & 99.37419 & 95.75366 & 0.0275 \\
\hline$r \leq 1$ & $r>1$ & 0.278931 & 43.67484 & 69.81889 & 0.8702 \\
\hline $\mathrm{r} \leq 2$ & $r>2$ & 0.139596 & 19.47528 & 47.85613 & 0.9935 \\
\hline$r \leq 3$ & $r>3$ & 0.059676 & 8.349115 & 29.79707 & 0.9955 \\
\hline$r \leq 4$ & $r>4$ & 0.046691 & 3.795804 & 15.49471 & 0.9193 \\
\hline $\mathrm{r} \leq 5$ & $r>5$ & 0.003473 & 0.257438 & 3.841466 & 0.6119 \\
\hline \multicolumn{2}{|c|}{ Hipótesis } & & & Valor crítico al & \\
\hline $\mathrm{H}_{0}$ & $\mathrm{H}_{1}$ & Eigenvalor & $\lambda_{\max }$ Valor & 0,05 & $P_{\text {valor }}{ }^{* *}$ \\
\hline \multicolumn{6}{|c|}{ Test de Máximo Eigenvalor para el rango de cointegración } \\
\hline \multicolumn{6}{|c|}{$\lambda_{\max }$ test } \\
\hline$r=0^{*}$ & $r=1$ & 0.528904 & 55.69935 & 40.07757 & 0.0004 \\
\hline$r=1$ & $r=2$ & 0.278931 & 24.19956 & 33.87687 & 0.4411 \\
\hline$r=2$ & $r=3$ & 0.139596 & 11.12617 & 27.58434 & 0.9621 \\
\hline$r=3$ & $r=4$ & 0.059676 & 45.5331 & 21.13162 & 0.9981 \\
\hline$r=4$ & $r=5$ & 0.046691 & 35.38366 & 14.26460 & 0.9046 \\
\hline$r=5$ & $r=6$ & 0.003473 & 0.257438 & 3.841466 & 0.6119 \\
\hline
\end{tabular}
cointegrantes. Los resultados se presentan en la tabla 5.

\footnotetext{
* El test de traza y de máximo eigenvalor, indican una ecuación cointegrante al nivel del $5 \%$ **P-valor de MacKinnon- Haug-Michelis (1999)
}

Tabla 5. Prueba de cointegración de Johansen
Fuente: elaboración propia con datos del anexo 2. 
Se observa que la hipótesis nula, que enuncia que las variables no están cointegradas, $(r=0)$, contra la alternativa, que expresa la existencia de uno o más vectores cointegrantes, $(r>0)$, muestra un valor del estadístico $\lambda_{\text {trace }}$ de 99,3742, el cual, al nivel de significancia del 0,05, excede su valor crítico (95.754). En consecuencia, se acepta que en el sistema de variables existe uno o más vectores cointegrantes. El estadístico $\lambda_{\max }$ valida este resultado, ya que la hipótesis nula $(r=0)$ contra la alternativa $(r=1)$ es claramente rechazada, pues el estadístico $\lambda_{\max }=55,69935$ excede al 0,05 su valor crítico (40.0776), con lo que se concluye que existe un único vector cointegrante. Para ambos estadísticos los P-valor confirman los resultados.

Los resultados de la prueba de cointegración confirman la existencia de una relación de largo plazo entre la ocupación generada en la economía informal y la economía formal a través del desempleo urbano, el salario mínimo real, el empleo generado en los sectores de industria y comercio y el crecimiento económico; en otras palabras, las variables del sistema de ecuaciones bajo análisis están cointegradas dado que la combinación lineal de ellas es estacionaria ( $\beta x_{t}=\varepsilon_{t}=0$ ), por lo tanto existe un término de corrección de error tal que cada variable del modelo responde a la desviación del equilibrio de largo plazo. Lo anterior implica que la dinámica de corto plazo de las variables mencionadas está influenciada por el grado de cualquier desviación del equilibrio de largo plazo en cualquiera de ellas. Por consiguiente, cuando las variables del sistema retornen al equilibrio de largo plazo, se conocerá más sobre los movimientos de las variables (o al menos de alguna de ellas) en respuesta a la magnitud del desequilibrio.

En resumen, la prueba de cointegración permite concluir que existe una relación de largo plazo, a la que corresponde una representación de error de corrección que debe ser estimada para conocer con más precisión el comportamiento de dichas variables a lo largo del tiempo; específicamente las respuestas frente a las desviaciones de equilibrio que se registren en el largo plazo y, en particular, lo referente a la ocupación originada en la economía informal.

\section{Resultados del vector de corrección de error}

Los MVCE son muy sensibles a la longitud de rezagos que incorporen. Un procedimiento común es estimar un VAR tradicional con los datos no diferenciados y utilizar el resultado que arroja la prueba de longitud óptima de rezagos de ese VAR. Con este fin, se estimó un VAR de orden dos, estableciendo el rezago óptimo para el MVCE a través del criterio de información 
de Akaike (AIC), el de Hannan y Quinn (HQ), el de información bayesiana de Schwarz (SC) y el criterio de error de predicción final de Akaike (FPE). El resultado sugirió el empleo de cuatro diferencias rezagadas (ver anexo 3) debido a que el MVCE con el criterio de información de Schwarz implica la ausencia de términos en diferencia rezagados, mientras que los demás criterios indican que se deben incluir cinco rezagos; lo anterior debido a que un VAR (p) corresponde a un VEC (p-1) (Lütkepohl, 2005).

Con lo anterior se procedió a correr el MVCE para el sistema de variables objeto de estudio, incluyendo en la ecuación de cointegración el término constante y la tendencia debido a que ambos se observan en el proceso generador de los datos. Así mismo, el modelo se ejecutó con un rango de cointegración igual a uno, $r=1$ y con 4 rezagos para los términos VAR en diferencias, de acuerdo con los resultados de la prueba de Johansen. Si bien el interés analítico del modelo es el vector cointegrante y los coeficientes de velocidad de ajuste asociados, los resultados de coeficientes de las matrices $\pi_{j}$ se puede consultar en el anexo 4 del MVCE estimado.

La tabla 6 presenta los resultados del vector cointegrante y de los coeficientes de velocidad de ajuste. Con $r=1$ y normalizado con respecto a la ocupación causada en la economía informal (Ocif), el vector cointegrante y los coeficientes de velocidad de ajuste encontrados ofrecen las tres evidencias descritas en el siguiente apartado.

\begin{tabular}{l|cccccc}
\hline \multirow{2}{*}{\multicolumn{1}{c|}{ Parametros }} & \multicolumn{6}{|c}{ Variables del sistema } \\
\cline { 2 - 7 } & $\Delta$ Ocif & $\Delta$ Dsu & \multicolumn{1}{c}{$\Delta$ Smr } & \multicolumn{1}{c}{$\Delta$ Emf } & \multicolumn{1}{c}{$\Delta$ Ecm } & \multicolumn{1}{c}{$\Delta$ Pibr } \\
\hline Coeficientes del vector & 1 & 0.609495 & 1.423174 & -0.291261 & -1.928213 & 2.154663 \\
cointegrante & & $(0.17304)$ & $(0.70224)$ & $(0.28287)$ & $(0.39979)$ & $(0.52332)$ \\
\multicolumn{1}{c|}{$\hat{\beta}_{i}^{\prime}$} & & {$[3.52223]$} & {$[2.02662]$} & {$[-1.02965]$} & {$[-4.82310]$} & {$[4.11733]$} \\
\hline Coeficientes del vector de & 0.235607 & $-0,172868$ & -0.045887 & 0.319017 & 0.447483 & 0.004702 \\
velocidad de ajuste & $(0.06674)$ & $-0,11807$ & $(0.02037)$ & $(0.08601)$ & $(0.06525)$ & $(0.02447)$ \\
\multicolumn{1}{c}{$\hat{\alpha}_{i}$} & {$[3.53021]$} & {$[-1.46409]$} & {$[-2.25315]$} & {$[3.70916]$} & {$[6.85764]$} & {$[0.19213]$} \\
\hline
\end{tabular}

Errores estándar en ( ) y estadísticos t en [ ]

\section{Análisis de los coeficientes del vector cointegrante}

1. De acuerdo con los resultados de los coeficientes $\beta$, la relación de equilibrio de largo plazo es:

Ocif- 0.6095Dsu-1.42Smr-0.29Emf-1.93Ecm-2.15Pibr $=0$

Esto es, la combinación lineal dada por (5) es una serie estacionaria. Al incluir la tendencia se tiene que

Ocif $=0.6095 \mathrm{Dsu}+1.42 \mathrm{Smr}-0.29 \mathrm{Em}-1.93 \mathrm{Ecm}+2.15 \mathrm{Pibr}-0.03752 t$
Tabla 6. Parámetros estimados del vector cointegrante y de velocidad de ajuste. Muestra ajustada: 2002.II 2019. IV (71 Observaciones incluidas después del ajuste)

Fuente: elaboración propia con datos del anexo 4. 
De forma que con un coeficiente de tendencia de signo negativo esperado y estadísticamente significativo (ver anexo 4), se confirma que, en el tiempo, un deterioro adicional en las variables del sistema, eventualmente, conduce a un incremento en la ocupación en la Economía Informal.

2. Exceptuando el empleo generado en el sector manufacturero formal, las demás variables son estadísticamente significativas.

3. Los coeficientes del vector cointegrante tienen los signos esperados.

\section{Restricción sobre los parámetros $\beta$}

De acuerdo con lo indicado en el punto 3 del apartado anterior, se prueba la hipótesis nula ${ }^{17}$ según la cual los signos de cada coeficiente contenidos en el vector son: $\beta=(1,1,-1,-1,1)$. Los resultados se muestran en la tabla 7.

Tabla 7. Prueba sobre las restricciones de los coeficientes $\beta$ del vector cointegrante

Fuente: elaboración propia con datos del anexo 5.

\begin{tabular}{ccccccc}
\hline & $\mathrm{H}_{0:}$ & Para & $\beta_{1}=1$, & $\beta_{2}=1$, & $\beta_{3}=1$ & \\
\hline $\begin{array}{c}\text { Número de } \\
\text { ecuaciones } \\
\text { cointegrantes }\end{array}$ & $\hat{\chi}^{2}$ & $\begin{array}{c}\text { Grados de } \\
\text { libertad }\end{array}$ & P-valor & $\begin{array}{c}\text { Rechazar al } \\
0.01\end{array}$ \\
\hline 1 & & 2,759405 & 2 & 0,25165 & No \\
\hline & $\mathrm{H}_{0:}$ & Para & $\beta_{4}=-1$, & $\beta_{5}=-1$, & $\beta_{6}=1$ & \\
\hline 1 & & 8.58371 & & 2 & 0.01368 & No \\
\hline
\end{tabular}

Dados los $p$-valor y con un nivel de significancia de 0,01 , la hipótesis nula resulta vinculante, es decir, no se pueden rechazar las restricciones impuestas a los coeficientes de las variables Ocif, Dsu, y Smr. Lo mismo ocurre con las restricciones indicadas sobre los coeficientes de Emf, Ecm y PIBr. De esta forma, se concluye que los resultados son consistentes con los signos esperados de la relación cointegrante de largo plazo.

\section{Análisis de los coeficientes del vector de velocidad de ajuste}

El interés particular de estos coeficientes radica en el sustancial alcance que tienen para trazar la dinámica de las variables del sistema. Cada valor $\alpha_{i}$ del vector de velocidad de ajuste mide el grado de respuesta de cada variable del sistema ante las desviaciones de equilibrio de largo plazo. Cuanto mayor sea $\alpha_{i}$ mayor será la respuesta a la desviación del período anterior

17 El estadístico para testear las restricciones sobre $\alpha$ y $\beta$ es $T \sum_{i=1}^{r}\left[\ln \left(1-\hat{\lambda}_{i}^{*}\right)-\ln \left(1-\hat{\lambda}_{i}\right)\right] \sim \chi^{2}$, donde $\hat{\lambda}_{i}$ y $\hat{\lambda}_{i}^{*}$ son las raíces características de los modelos sin restricción y con restricción, con grados de libertad igual al número de restricciones colocadas sobre los parámetros (ver Enders, 2004). 
del equilibrio a largo plazo. En el extremo opuesto, valores muy pequeños significan que las variables de interés en el corto plazo no responden al error de equilibrio del último período (Enders, 2004, p. 329). Las evidencias encontradas se resumen en dos puntos:

1. El signo de los coeficientes evidencia que el sistema converge hacia el equilibrio de largo plazo (tabla 6). En efecto, de un lado se observa que $\alpha_{2}$ y $\alpha_{3}<0$, y de otro lado que $\alpha_{1^{\prime}} \alpha_{4^{\prime}} \alpha_{5}$ y $\alpha_{6}<0$, lo que significa que mientras el desempleo urbano (Dsu) y el salario mínimo (Smr) disminuyen, la ocupación en la economía informal (Ocif), el empleo en la industria manufacturera (Emf) y en el comercio (Ecm), así como el PIBr, se incrementan en respuesta a una desviación positiva en el equilibrio de largo plazo. De esta manera se compensa la desviación o error y se vuelve a la senda del equilibrio.

2. De acuerdo con la dimensión de los parámetros y sus valores $t$, la variable que más rápido responde ante desequilibrios de corto plazo y converge con más velocidad al equilibrio de largo plazo es el empleo generado en el comercio y en la industria, seguido por la ocupación en la economía informal y el salario mínimo. Por su parte, la significancia estadística de los coeficientes de velocidad de ajuste asociados al desempleo urbano y al $\mathrm{PIBr}$, indican que en el corto plazo estas dos variables no responden al error de equilibrio del último período.

\section{Restricciones sobre los parámetros a}

Es importante probar estadísticamente si en el sistema cointegrado existe alguna variable que no responda a la discrepancia de la relación de equilibrio de largo plazo. En la tabla 8 se presenta la hipótesis nula que restringe a cero cada uno de los coeficientes a y los respectivos estadísticos, hi cuadrado y p-valor.

\begin{tabular}{cccccc}
\hline \multirow{2}{*}{$\mathrm{H}_{0}$} & $\mathrm{r}$ & \multirow{2}{*}{$\hat{\chi}^{2}$} & \multirow{2}{*}{ P-valor } & \multicolumn{2}{c}{ Rechazar } \\
\cline { 5 - 6 } & & & 0.01 & 0.10 \\
\hline$\alpha_{1}=0$ & 1 & 11,6339 & 0.00065 & $\mathrm{Si}$ & $\mathrm{Si}$ \\
$\alpha_{2}=0$ & 1 & 3,0176 & 0.0823 & $\mathrm{No}$ & $\mathrm{Si}$ \\
$\alpha_{3}=0$ & 1 & 6,7614 & 0.0093 & $\mathrm{Si}$ & $\mathrm{Si}$ \\
$\alpha_{4}=0$ & 1 & 14,101 & 0.00017 & $\mathrm{Si}$ & $\mathrm{Si}$ \\
$\alpha_{5}=0$ & 1 & 36,10028 & 0.00000 & $\mathrm{Si}$ & $\mathrm{Si}$ \\
$\alpha_{6}=0$ & 1 & 0,048253 & 0.826132 & $\mathrm{No}$ & $\mathrm{No}$ \\
\hline
\end{tabular}

Tabla 8. Prueba de Restricciones sobre los coeficientes de velocidad de ajuste 
Dados los p-valor y con un nivel de significancia de 0,01 , la hipótesis nula para cada coeficiente $\alpha_{i}$ no es vinculante, es decir, se rechazan las restricciones impuestas a los coeficientes de ajuste de velocidad asociados a las variables Ocif, Smr, Emf y Ecm. En cuanto al coeficiente de la variable desempleo urbano (Dsu), se rechaza al 0,1 ; sin embargo, no ocurre lo mismo con el coeficiente del PIBr, que estadísticamente no es diferente de cero, es decir, no responde ante desequilibrios de corto plazo en el sistema de variables, por lo cual se concluye que el PIBr es una variable débilmente exógena en el sistema de variables analizado. En general, este resultado sugiere que el $\mathrm{PIBr}$, aunque no responda a la discrepancia de la relación de equilibrio de largo plazo, sí responde a los cambios originados en choques estocásticos (representados por los términos de error) y algunos términos del VAR; es decir, evoluciona independientemente de los eventos que ocurran en la economía informal y en el empleo formal generado en la industria y el comercio.

\section{Descomposición de varianza}

Este procedimiento permite una correcta aproximación al impacto relativo que generan los choques experimentados por las variables del sistema sobre alguna variable especifica que lo conforman. Con este fin, se separa la variación en el error de pronóstico de la variable especifica entre los distintos componentes de innovación, lo cual significa que la descomposición de varianza permite estimar que porcentaje del comportamiento futuro de la variable especificada es atribuible a su propio choque, así como a los choques de las demás variables del sistema.

La descomposición de varianza, para las variables ocupación en la economía informal, desempleo urbano y salario mínimo real se muestra en la tabla 9 para un horizonte de tiempo de 12 trimestres. En la tabla 10 se presentan los resultados para el empleo generado en los sectores de manufactura y comercio, así como para el PIBr.

En la tabla 9 se aprecia la descomposición de Ocif, Dsu y Smr para todo el horizonte de tiempo y los choques con los que contribuye cada una de las seis variables del sistema para explicar el impacto sobre la ocupación que se origina en la economía informal, el desempleo y el salario mínimo. Para la variable Ocif, en los tres años, se observa que el 84,5\%, en promedio, de la varianza de los ocupados en la economía informal se explica por innovaciones en la misma variable. Sin embargo, aunque toda la varianza en el primer trimestre se explica por los choques en la misma variable, entre el segundo trimestre y el sexto trimestre un poco más del $13 \%$ de la varianza de Ocif 
se explica por los choques experimentados, principalmente, en el salario mínimo (6,74 \%, en promedio) y en el desempleo urbano $(2,74 \%$, en promedio). El empleo manufacturero aporta, en promedio, 1,71 \% de la explicación, mientras que el empleo en el comercio y el $\mathrm{PIBr}$ solamente explican, respectivamente, el 1,24 y el 0,6\%. Dentro de los seis primeros trimestres, si bien los choques de todas las variables del sistema contribuyen a explicar la varianza de la ocupación generada dentro de la economía informal, por su dimensión se evidencia que no tienen una fuerte incidencia sobre Ocif.
Tabla 9. Descomposición de varianza de la variable ocupación en la Economía Informal, desempleo urbano y salario mínimo

\begin{tabular}{|c|c|c|c|c|c|c|c|c|c|c|c|c|c|c|c|c|c|c|c|c|c|}
\hline \multirow{2}{*}{ Período } & \multicolumn{7}{|c|}{$\mathrm{OCIF}$} & \multicolumn{7}{|c|}{ DSU } & \multicolumn{7}{|c|}{ SMR } \\
\hline & S.E. & $\mathrm{OCIF}$ & DSU & SMR & EMF & $\mathrm{ECM}$ & PIBR & S.E. & OCIF & DSU & SMR & EMF & $\mathrm{ECM}$ & PIBR & S.E. & OCIF & DSU & SMR & EMF & ECM & $\mathrm{PIBr}$ \\
\hline 1 & 0,021 & 100,0 & 0,0 & 0,0 & 0,0 & 0,0 & 0,0 & 0,037 & 0,58 & 99,42 & 0,00 & 0,00 & 0,00 & 0,00 & 0,006 & 0,16 & 0,00 & 099,84 & 0,00 & 0,00 & 0,00 \\
\hline 2 & 0,028 & 92,28 & 1,77 & 4,05 & 1,37 & 0,12 & 0,40 & 0,048 & 9,27 & 79,69 & 4,82 & 0,08 & 3,07 & 3,08 & 0,008 & 0,87 & $7 \quad 0,80$ & 094,30 & 3,52 & 0,507 & 0,00 \\
\hline 3 & 0,033 & 87,99 & 3,26 & 5,79 & 1,77 & 0,82 & 0,36 & 0,056 & 22,98 & 62,17 & 3,43 & 0,23 & 2,25 & 8,94 & 0,010 & 0,75 & 3,75 & 581,11 & 10,71 & 1,44 & 2, \\
\hline 4 & 0,035 & 86,66 & 3,44 & 6,90 & 1,64 & 0,71 & 0,64 & 0,066 & 34,49 & 47,96 & 2,56 & 0,47 & 3,36 & 11,16 & 0,011 & 0,92 & 2 8,17 & $7 \quad 74,34$ & 12,85 & 1,92 & 1,79 \\
\hline 5 & 0,038 & 84,85 & 2,91 & 8,60 & 2,06 & 0,75 & 0,84 & 0,077 & 32,15 & 44,75 & 5,48 & 0,72 & 3,89 & 13,01 & 0,013 & 2,43 & 7,25 & $5 \quad 74,84$ & 9,97 & 3,83 & 1, \\
\hline 6 & 0,043 & 83,08 & 2,34 & 8,37 & 1,69 & 3,79 & 0,74 & 0,086 & 34,63 & 41,46 & 5,72 & 0,92 & 3,11 & 14,15 & 0,015 & 4,80 & 6,00 & $0 \quad 72,46$ & 11,52 & 3,79 & 1, \\
\hline 7 & 0,049 & 80,98 & 1,77 & 10,12 & 1,32 & 5,09 & 0,74 & 0,096 & 37,19 & 37,21 & 5,18 & 0,83 & 3,19 & 16,41 & 0,016 & 4,74 & 6,95 & $\begin{array}{lll}5 & 70,59\end{array}$ & 12,59 & 3,38 & 1 , \\
\hline 8 & 0,054 & 79,76 & 1,93 & 10,03 & 1,12 & 6,52 & 0,64 & 0,106 & 40,93 & 31,05 & 5,78 & 0,76 & 4,07 & 17,41 & 0,017 & 4,97 & 72,02 & 265,75 & 12,31 & 2,82 & 2 , \\
\hline 9 & 0,058 & 80,75 & 1,72 & 9,72 & 0,99 & 6,26 & 0,57 & 0,118 & 39,72 & 28,58 & 8,19 & 0,62 & 6,29 & 16,61 & 0,0 & 5,24 & 11,66 & 666,28 & 11,33 & 3,21 & 2 , \\
\hline 10 & 0,062 & 80,40 & 1,55 & 10,07 & 0,89 & 6,29 & 0,8 & 0,126 & 40,39 & 27,55 & 9,21 & 0,80 & 5,68 & 16,37 & 0,020 & 7,49 & 10,62 & 264,99 & 11,75 & 3,14 & 2 , \\
\hline 11 & 0,065 & 79,25 & 1,40 & 10,51 & 0, & 7,2 & 0, & & & 25,91 & & 0,77 & 5,59 & 17,14 & & 4 & 10,89 & 963,37 & 12,37 & 3,15 & 2 , \\
\hline 12 & 0,068 & 77,74 & 1,36 & 11,79 & 0,77 & 7,48 & 0,86 & 0,142 & 42,93 & 23,41 & 9,04 & 0,77 & 5,88 & 17,9 & 0,022 & 8,53 & 13,37 & 760,46 & 12,35 & 2,91 & \\
\hline
\end{tabular}

También se observa que en la explicación de la varianza de Ocif, entre el séptimo trimestre y el último trimestre, los choques en el Smr y los generados en el empleo del sector comercio cobran importancia, mientras que los ocasionados en el desempleo urbano y el empleo manufacturero decaen. En efecto, en promedio para los seis trimestres, mientras que el 79,8 $\%$ de la varianza de esta variable se explica por innovaciones en ella misma, el resto se explica por los choques en las demás variables del sistema. Así, las innovaciones registradas en las dos primeras variables explican, en promedio, el 16,82 \% de la varianza de Ocif en ese período, 10,34 \% en el Smr y $6,48 \%$ en el empleo generado en $\mathrm{Ecm}$.

De esta forma, se encuentra que en todo el período las innovaciones ocurridas en el salario mínimo y en el empleo en el sector comercio explican, en forma creciente, el error de pronóstico de Ocif; es decir, su movimiento o comportamiento futuro. A partir del segundo trimestre el desempleo urbano también explica el error de pronóstico de manera decreciente y el mismo patrón se observa con el empleo en el sector manufacturero, pero a partir del quinto trimestre. Por último, los choques en el $\mathrm{PIBr}$ explican muy poco. De todas formas, los choques en estas dos últimas variables no alcanzan a explicar más del 1,2\% del error de pronóstico de Ocif en los tres años, lo que
Fuente: elaboración propia con datos del anexo 7. 
prueba su escasa dependencia respecto a esas variables, especialmente del PIBr. Es decir, la evolución futura de Ocif es altamente independiente de los choques que registren estas dos variables. De acuerdo con lo establecido, se puede afirmar que debido a que la varianza de Ocif, se explica, fundamentalmente, por los choques en sí misma su evolución ha sido altamente independiente de las sorpresas ocurridas en todas las demás variables del sistema.

Es importante subrayar que la evidencia de bajo impacto estadístico del desempleo urbano sobre la varianza de la variable Ocif significa que la primera no es muy útil para el pronóstico de la segunda, lo cual apuntala la intuición de que solo una pequeña parte de los trabajadores formales que pierden su empleo pasan a la informalidad; tal es la importancia del débil feedback de la variable Dsu hacia la variable Ocif. Un resultado que llama la atención es el carácter liviano de las innovaciones del salario mínimo, (8 \% en promedio para todo el período) para explicar la varianza de la ocupación informal, pues, como ya se ha visto, a esta variable se le atribuye un peso sustancial en la explicación de los niveles de la ocupación informal y del desempleo. Por lo anterior, los datos de descomposición de varianza aquí presentados indican una posible sobreestimación del impacto del salario mínimo sobre la ocupación informal, cuya la varianza, como se ha demostrado, se explica por sus propios choques.

Continuando con la tabla 9, se aprecia en el primer trimestre que el $99,4 \%$ de la varianza del desempleo urbano se explica por los choques en la misma variable. Sin embargo, a partir del segundo trimestre y hasta el último, solamente el 40,89\%, en promedio, es explicado por choques en ella misma, mientras que el otro 59,11 \%, en promedio, es explicado por las innovaciones experimentadas en las demás variables del sistema. Así, entre el segundo y el último trimestre se observa que, en promedio, el 34,23\% de la varianza de la variable Dsu se explica por los choques experimentados en Ocif, 13,84 \% por lo choques en el $\mathrm{PIBr}, 6,2 \%$ por los choques en el Smr, 4,22 $\%$, en promedio, atribuible a Ecm y solamente $0,63 \%$ se explica por las sorpresas en el empleo manufacturero (Emf). Lo anterior evidencia que la evolución futura del desempleo urbano ha sido marcadamente dependiente de las innovaciones experimentadas en la economía informal, en el producto y en el salario mínimo. De tal forma, Dsu es una variable altamente dependiente de las sorpresas en las demás variables del sistema, pues su varianza se explica, principalmente, por los choques ocurridos en ellas, especialmente por los choques ocurridos en la ocupación de la Economía informal y en el PIB. 
Para terminar con los resultados de la tabla 9, para la variable Smr se puede ver que a partir del segundo trimestre hasta el trimestre final el 71,68 $\%$ de su varianza se explica por los choques propios y $28,32 \%$ por las innovaciones en las demás variables del sistema. Es de destacar la importancia de los choques en las variables Emf, Dsu y Ocif para explicar la varianza del salario mínimo, cuyas innovaciones explican, en promedio, el 11,03, 8,31 y $4,43 \%$, respectivamente.

Pasando a la tabla 10, se evidencia que si bien el comportamiento de los errores de pronóstico de las variables de empleo en los sectores de manufactura y comercio obedecen principalmente a los choques experimentados por ellas mismas, en el caso de Emf se observa que desde el tercer trimestre hasta el trimestre doce, la varianza se explica cada vez más por las innovaciones en el Smr y en Ecm. Así, en el tercer trimestre la varianza se explica por un choque de 7,04 \% en Smr y 4,34 \% en Ecm, mientras que en el trimestre 12 esos porcentajes pasan a 15,3 y 10,16\%, respectivamente. Obsérvese aquí que los choques en la ocupación de la economía informal y en el PIBr, con el paso del tiempo, adquieren una modesta y decreciente incidencia en la explicación de la varianza de EMF.
Tabla 10. Descomposición de varianza de las variables empleo en el sector manufacturero, empleo en el sector comercio y $\mathrm{PIBr}$

\begin{tabular}{|c|c|c|c|c|c|c|c|c|c|c|c|c|c|c|c|c|c|c|c|c|}
\hline \multirow{2}{*}{ Período } & \multicolumn{7}{|c|}{ EMF } & \multicolumn{7}{|c|}{ ECM } & \multicolumn{6}{|c|}{$\mathrm{PIBr}$} \\
\hline & S.E. & $\mathrm{OCIF}$ & DSU & SMR & EMF & ECM & ? IBR & S.E. & OCIF & DSU & SMR & MF & $\mathrm{ECM}$ & ?BRR & S.E. & $\mathrm{OCIF}$ & DSU & SMR & EMF & ECM PIBr \\
\hline 1 & 0,03 & 0,82 & 7,34 & 2,38 & 89,45 & 0,00 & 0,00 & 0,021 & 3,2 & 1,8 & 13,1 & 3,4 & 78,5 & 0,00 & 0,01 & 3,55 & 0,77 & 0,15 & 8,01 & $3,88 \quad 83,63$ \\
\hline 2 & 0,03 & 0,56 & 5,02 & 4,09 & 85,53 & 4,80 & 0,00 & 0,021 & 5,4 & 2,4 & 12,8 & 4,8 & 74,6 & 0,00 & 01 & 3,67 & 0,54 & 0,13 & 4,92 & $8,6982,05$ \\
\hline 3 & 0,04 & 0,77 & 4,68 & 7,04 & 81,61 & 4,34 & 55 & 24 & 9,9 & 2,0 & 23,6 & ,2 & 59,8 & 0,36 & 01 & 66 & 0,34 & 1,14 & 4,01 & $, 42 \quad 80,42$ \\
\hline 4 & 0,05 & 0,58 & 3,90 & 13,27 & 76,52 & 4,56 & 1,17 & 0,028 & 18,2 & 11,7 & 21,8 & 3,3 & 44,1 & 0,82 & 0,02 & 10,19 & 0,23 & 3,89 & 3,20 & $6,10 \quad 76,39$ \\
\hline 5 & 0,05 & 1,08 & 3,52 & 12,36 & 75,10 & 5,91 & 2,03 & 0,030 & 21,4 & 13,5 & 19,5 & 3,0 & 39,2 & 3,51 & 0,02 & 18,31 & 0,19 & 5,75 & 2,52 & $6,44 \quad 66,79$ \\
\hline 6 & 06 & 2,42 & 3,39 & 13,1 & 72,29 & 6,96 & 1,82 & 10 & 31,6 & 12,1 & 17 & 2,0 & 33 & 2,5 & 0,02 & 20,35 & 0,74 & 8,55 & 1,94 & $5,7262,70$ \\
\hline 7 & 0,06 & 2,22 & 3,58 & 13,47 & 71,05 & 7,95 & 1,74 & 0,034 & 34,7 & 12,0 & 17,0 & 2,4 & 30,7 & 3,22 & 0,03 & 20,79 & 0,84 & 10,29 & 1,55 & $6,17 \quad 60,36$ \\
\hline 8 & 0,06 & 2,01 & 3,18 & 13,88 & 69,36 & 9,50 & 2,07 & 0,036 & 36,1 & 12,8 & 19,1 & 2,1 & 26,9 & 2,98 & 0,03 & 20,26 & 0,82 & 11,91 & 1,29 & $6,15 \quad 59,58$ \\
\hline 9 & 0,07 & 1,78 & 3,05 & 4,1 & 70,76 & 8,43 & 1,87 & 0,038 & 36,7 & 15,3 & 18,1 & & 24,7 & 2,89 & 0,03 & 19,44 & 0,83 & 13,94 & 1,11 & $5,98 \quad 58,70$ \\
\hline 10 & 0,07 & 1,68 & 2,90 & 13,76 & 70,30 & 9,58 & 1,77 & 0,040 & 41,0 & 14,9 & 16,7 & 2,0 & 22,6 & 2,79 & 0,03 & 19,59 & 0,87 & 14,80 & 0,96 & $6,55 \quad 57,22$ \\
\hline 11 & 0,08 & 1,69 & 3,25 & 14,00 & 69,66 & 9,68 & 1,73 & 0,042 & 43,9 & 14,2 & 16,8 & 1,9 & 20,7 & 2,56 & 0,04 & 19,85 & 0,995 & 16,02 & 0,83 & $6,7055,60$ \\
\hline 12 & 0,08 & 1,65 & 2,95 & 15,27 & 68,36 & 10,16 & 1,61 & 0,045 & 44,8 & 14,7 & 17,3 & 1,7 & 19,0 & 2,47 & 0,04 & 19,93 & 1,017 & 16,87 & 0,74 & $6,99 \quad 54,46$ \\
\hline
\end{tabular}

Ordenamiento de Cholesky: OCIF DSU SMR EMF ECM PIBR

Como se puede observar en la tabla 10, en el primer trimestre, el 78,5 $\%$ de la varianza de la variable Ecm se explica por los choques experimentados por ella misma. Sin embargo, con el transcurrir de los períodos esto deja de ser así, de forma que en el período 12 esa cifra cae a $19 \%$. El resto de la varianza de Ecm es explicado por los choques en las demás variables del sistema, especialmente por los choques ocurridos en la ocupación informal, en el salario mínimo y en el desempleo urbano. De acuerdo con lo anterior, se encuentra que, en promedio, durante los doce trimestres solamente el
Fuente: elaboración propia con datos del anexo 7. 
$39,52 \%$ de la varianza del empleo en el sector comercio es explicada por las sorpresas en la misma variable, mientras que, en promedio, el 60,48 \% de la varianza del empleo en ese sector se explica por los choques en Ocif $(27,24$ $\%), \operatorname{Smr}(17,77 \%)$, Dsu (10,62 \%), Emf (2,8 \%) y $\mathrm{PIBr}(2,05 \%)$. De tal forma, Ecm es una variable cuya varianza se explica, principalmente, por los choques en las demás variables del sistema, en particular por los ocurridos en la ocupación de la Economía informal y en la economía formal manifiestos a través del salario mínimo y el desempleo en el mercado laboral urbano.

Con lo anterior se evidencia que la evolución futura del empleo generado en el comercio será marcadamente dependiente de las innovaciones experimentadas en esas variables. Por otra parte, el cercano vínculo entre la Ocif y el Ecm obedece, como ya se mencionó, a que la mayoría de las actividades productivas de los ocupados en la economía informal se realizan en el sector comercio, mantenimiento y reparación.

Finalmente, se destaca la importancia de los choques en las variables Ocif y Smr para explicar varianza de la variable PIBr. En efecto, hasta el tercer trimestre, el $80 \%$ de su varianza se explica por los choques propios. Pero a partir del cuarto período esa varianza empieza a ser explicada por los choques en la ocupación informal. De hecho, su participación pasa de 10,2 \% en el cuarto trimestre a 19,9\% en el trimestre doce. Esta dinámica se hace más evidente cuando se observa que, en promedio, durante los doce trimestres solamente el $66,49 \%$ de la varianza del $\mathrm{PIBr}$ se explica por las sorpresas en la misma variable, mientras que el resto de la varianza se explica, principalmente, por los choques en la ocupación informal [Ocif] (15,21\%), el salario mínimo [Smr] (8,62 \%) y en el empleo del sector comercio [Ecm] $(6,40 \%)$. A estos choques le siguen los ocurridos en el empleo manufacturero y en el desempleo urbano, con 2,59 y $0,68 \%$, respectivamente. Este resultado no solo deja ver la importancia que tiene para la economía del país la contribución de las unidades productivas informales a la generación de bienes y servicios e ingresos, sino también, como ya se anotó, indica que la economía informal y la ocupación generada en ella es un componente básico de la economía como un todo, con una dinámica propia que impacta acentuadamente el movimiento del producto y el ingreso nacional.

\section{Impulso-respuesta}

Siguiendo a Enders, un choque en la $i$-ésima variable no solo afecta directamente la $i$-ésima variable, sino que se transmite a todas las otras variables endógenas a través de la estructura dinámica (retraso) del sistema de 
ecuaciones de un VAR. Una función de impulso-respuesta permite observar con detalle tales interrelaciones entre las variables del sistema e indaga el efecto de un único choque en el tiempo de las innovaciones en los valores actuales y futuros de las variables endógenas. Igual que en el análisis VAR tradicional, en un MVEC las funciones impulso-respuesta se emplean para obtener información sobre la interacción de las variables, y aunque el MVCE solo aplica con variables I(1), que no tienen una representación de promedio móvil como en un modelo $\mathrm{VAR}^{18}{ }^{18}$ se puede tener una representación de las variables en términos de los errores de predicción de ellas, con lo cual ambos tipos de impulso-respuesta son equivalentes y únicamente se diferencian en la escala, Lütkepohl (2005, p. 264).

Como el principal propósito del análisis es la ocupación generada en el ámbito de la economía informal en el dominio urbano y su relación con las demás variables del sistema, en esta sección se presentan los resultados de las respuestas de la variable Ocif ante la ocurrencia de perturbaciones de una desviación estándar en las variables Dsu, Smr, Emf, Ecm y PIBr. Así mismo, por ser de particular interés, se examina el resultado impulso-respuesta del desempleo urbano debido a innovaciones en el salario mínimo real. Los resultados se presentan en las figuras 2 y 3 .

En cuanto a la respuesta de Ocif, en el panel (a) de la figura 2 el eje vertical muestra el impacto sobre el número de ocupados en la economía informal, mientras que el eje horizontal da cuenta de las repuestas que siguen después de una perturbación de una desviación estándar ocurrida en ella misma y en las variables salario mínimo, desempleo urbano y $\mathrm{PIBr}$. Como se esperaba, la respuesta más dinámica en el número de ocupados informales corresponde al choque aleatorio en la misma variable Ocif, la cual, a partir del trimestre 7, después de haber crecido cerca de 1,2\%, empieza a revertir el nuevo nivel, y en el trimestre 10 vuelve a caer para luego estabilizarse ${ }^{19}$ en el largo plazo. 
Figura 2. Respuesta de la ocupación en la economía informal ante choques propios, desempleo urbano, salario mínimo y PIB

(2001.I-2019.I) (a)

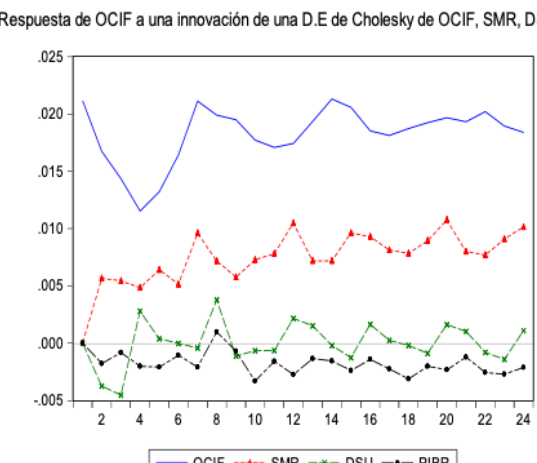

(b)

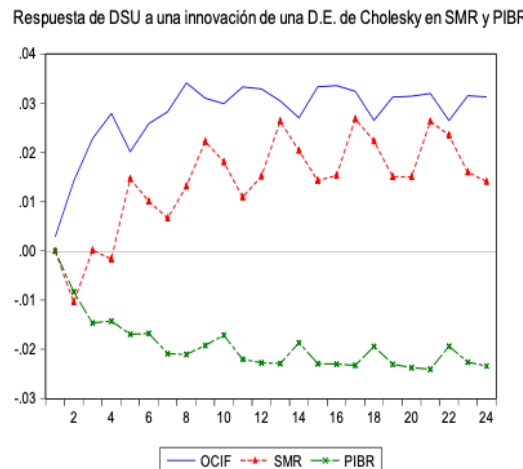

En la figura 2 también se aprecia que una innovación positiva de una desviación estándar en el salario mínimo durante el segundo trimestre incrementa en poco más de 0,5 \% la ocupación en la economía informal, cifra que aumenta hasta el $1 \%$ y se estabiliza alrededor de este a partir del noveno trimestre. Este resultado sencillamente sugiere que ante un incremento en costos laborales en la economía formal se incrementa ligeramente la ocupación en la economía informal debido a que esta capta trabajadores que no pueden ser empleados a cierto nivel de costos laborales. Sin duda, lo anterior es consistente con la evidencia encontrada en el análisis de descomposición de varianza, donde se halló que los choques experimentados en el salario mínimo, contrario a lo que comúnmente se cree, tienen una fuerza poco substancial para explicar la varianza de la ocupación en el ámbito de la economía informal. Este resultado, en materia de política, sugiere que las medidas económicas orientadas a reducir el salario mínimo seguramente tendrán un moderado y limitado efecto para reducir la ocupación en la economía informal, lo cual permite entender lo subrayado en este sentido en la sección de revisión de antecedentes.

De otra parte, en correspondencia con los hallazgos en el análisis de descomposición de varianza, se observa que una innovación en el desempleo urbano incrementa levemente la ocupación informal durante un año, no más de $0,4 \%$ en los nueve trimestres posteriores a la perturbación. A partir del noveno trimestre, el impacto sobre sobre la ocupación informal pierde fuerza y se diluye a lo largo del horizonte de tiempo. El resultado es interesante porque, contrario a lo que se cree, insinúa alta independencia entre la ocupación causada en la Economía Informal y el alto desempleo que caracteriza al mercado laboral urbano. 
Vale la pena destacar que la fuerza moderada de los choques del desempleo urbano para explicar la variabilidad de Ocif se ajusta a la hipótesis de que la persistencia de la ocupación informal en Colombia se debe al hecho histórico de que la economía formal ha carecido de la capacidad suficiente para absorber, por lo menos, un alto porcentaje de la población en edad de trabajar. ${ }^{20}$ Por tal razón, se observa en los resultados de descomposición de varianza que los movimientos de la ocupación informal se explican exiguamente por el desempleo urbano. Finalmente, contrario a lo observado en la economía formal, el desempleo no es un problema de la economía informal.

Confirmando los resultados de descomposición de varianza, se observa que los impulsos en el $\mathrm{PIBr}$ no producen mayor respuesta de Ocif; en otras palabras, se observa una relación más directa y estrecha entre la ocupación informal, el salario mínimo y el desempleo urbano y una relación más autónoma entre Ocif y PIBr.

Pasando al panel (b), se aprecia que las innovaciones en la ocupación informal impactan fuertemente el desempleo urbano, incidiendo en su variabilidad hasta aproximadamente el octavo trimestre, momento a partir del cual se estabiliza. Esto muestra que detrás de los choques positivos en la ocupación de la economía informal se tienen importantes niveles de desempleo formal urbano. Este resultado es consistente con lo encontrado en la descomposición de varianza de la variable desempleo urbano, donde se observa que, en promedio para los tres años, el 34,23\% de su varianza se explica por los choques en Ocif. Así mismo, se evidencia que las perturbaciones en el salario mínimo real inducen un importante aumento en el nivel de desempleo en el ámbito de la economía formal. En cuanto a las innovaciones negativas registradas en el $\mathrm{PIBr}$, como es de suponer, estas impactan marcadamente el desempleo urbano, especialmente entre el segundo y el noveno trimestre.

Por último, como se ha visto con la mayoría de las variables, en la figura 3 se observa que la respuesta más dinámica del salario mínimo corresponde a las innovaciones en la misma variable, la cual a partir del quinto trimestre se mantiene en el largo plazo. De esta manera, la respuesta de Smr ante las innovaciones en el Emf evidencia un efecto positivo hasta el trimestre tres, que posteriormente persiste en el horizonte temporal completo, lo cual es

20 De hecho, durante el período de análisis, con una tasa global de participación (TGP) media de $65 \%$, la tasa promedio de ocupación laboral urbana apenas alcanza el $57 \%$, que puede caer varios puntos cuando se presentan incrementos en la TGP. 
consistente si se recuerda que aquí el Smr se considera como una variable aproximada de los costos laborales.

Figura 3. Respuestas del salario mínimo ante choques en el desempleo urbano y en el empleo del sector manufacturero (2001.I-2019.IV)

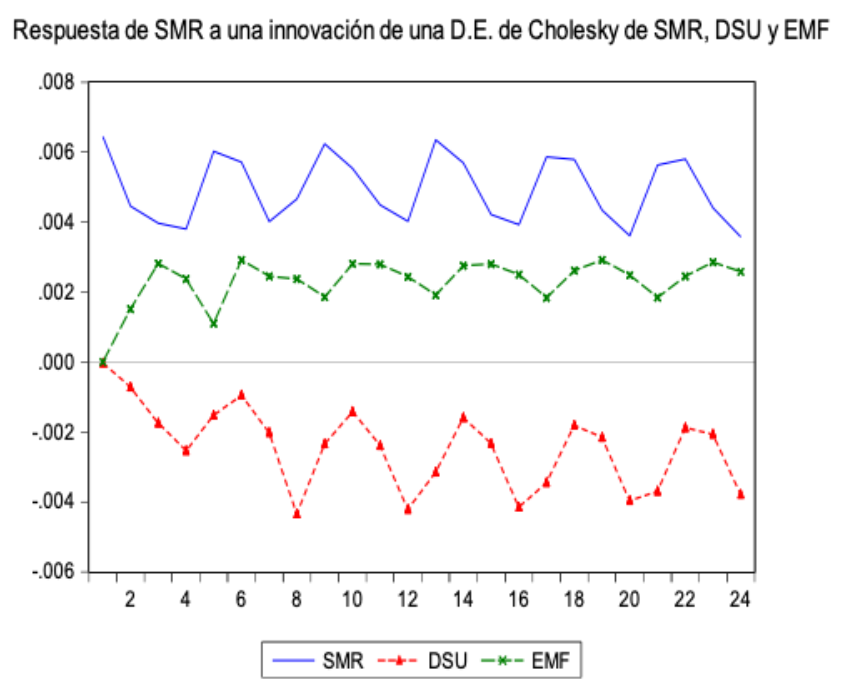

Fuente: elaboración propia.

Resumiendo, se puede afirmar que los resultados del análisis impulso-respuesta son aceptablemente consistentes con los resultados de descomposición de varianza. Estos, a su vez, confirman las respuestas dinámicas de las variables conforme a los supuestos teóricos del modelo tomados de los hallazgos empíricos reseñados en la primera sección.

\section{DIAGNÓSTICO DEL MODELO-ANÁLISIS DE RESIDUALES}

Para establecer la validez del MVCE estimado se examinó si sus residuales cumplían con los supuestos de ruido blanco. En tal sentido, las pruebas estadísticas realizadas de correlación serial, normalidad y de heteroscedasticidad permitieron concluir que los residuales del modelo VEC estimado tienen media cero, no presentan autocorrelación y son de varianza constante en todas las observaciones. En efecto, la prueba LM (Lagrange Multiplier Tests) - cuya hipótesis nula es que no existe correlación serial en los residuos hasta el rezago de orden 12- no fue rechazada, dados los p-valores substancialmente superiores a los niveles convencionales de significancia en todos los órdenes de rezago; es decir, los residuos no presentan autocorrelación hasta 12 trimestres atrás.

De igual forma, la hipótesis nula de residuales multivariados normales del MVCE no fue rechazada de acuerdo con los $p$-valor substancialmente 
superiores a los niveles convencionales de significancia asociados tanto a la prueba de Jarque Vera como a los componentes de skewness y curtosis. Por último, los resultados de la prueba para cada uno de los componentes, así como la prueba conjunta para todas las ecuaciones del modelo, no rechazan la hipótesis nula de no heteroscedasticidad; de hecho, la prueba conjunta de varianza constante en los residuales se acepta con un $p$-valor de 0,2195 . Todos los resultados se encuentran en el anexo 8.

\section{CONCLUSIONES}

Tal como reconoce el club al que recién ingreso Colombia, la OCDE, la ocupación en la economía informal en el país sigue siendo muy alta pese a todos los esfuerzos de formalización realizados en los últimos 20 años. Una de las razones principales para ello -identificada en la sección titulada "La efectividad de la política económica" — está en que los responsables de la política económica, además de desconocer factores estructurales e históricos de la economía colombiana, y de atribuir simplistamente al salario mínimo, sus incrementos y su impacto en el nivel de desempleo los factores últimos que explican la ocupación informal, elaboran políticas no encaminadas a beneficiar en el mediano y largo plazo al núcleo duro de la economía informal, es decir, los ocupados por cuenta propia. Por el contrario, esas medidas por lo general han favorecido al segmento de empresas empleadoras informales, también denominados empleadores o patronos. No obstante, pese a los pobres resultados hasta ahora alcanzados, los formuladores de política continúan obstinadamente con el mismo criterio de diseño, tal como lo comprueba el CONPES 3956 de enero de 2019.

Lo anterior sugiere que cualquier medida de política pública que pretenda reducir significativamente la ocupación informal exige que su núcleo duro, que es el más numeroso y vulnerable, sea atendido prioritariamente. Por consiguiente, con tal fin y en un esfuerzo de largo plazo, se requiere reconsiderar los criterios empleados en la elaboración de las medidas económicas. Más concretamente, por tratarse de un problema ligado a la erradicación de la pobreza extrema, la falta de oportunidades y la desigualdad en la distribución del ingreso y la concentración de la riqueza, se hace necesario implementar una estrategia integral dirigida al núcleo duro de la informalidad. Mucho más allá de políticas de flexibilización laboral, un programa global de largo plazo exige elaborar políticas económicas y sociales 
que tengan como centro el empleo productivo para toda la población, el acceso real a la seguridad social y a la educación de alta calidad, junto con estrategias de ampliación de mercados y apoyos fiscales y tributarios progresistas que estimulen el empresariado comprometido.

Pasando a la evidencia econométrica, los resultados de cointegración dan cuenta de la existencia de una relación de equilibrio de largo plazo entre la ocupación originada en la economía informal y la economía formal, a través del salario mínimo, el desempleo urbano, el empleo formal en los sectores de la manufactura y comercio y el $\mathrm{PIBr}$, indicando así que estas variables no se mueven independientemente unas de las otras y que influyen recíprocamente entre sí. La cointegración de esta variables implica la existencia de un mecanismo de corrección de error que hace que cada variable del modelo responda a la desviaciones de equilibrio de largo plazo. Esto quiere decir que la dinámica de corto plazo de las variables mencionadas son influenciadas por el grado de cualquier desviación del equilibrio de largo plazo en cualesquiera de ellas. Por consiguiente, cuando las variables del sistema retornan al equilibrio de largo plazo, se pueden establecer los movimientos de las variables (o al menos de alguna de ellas) en respuesta a la magnitud del desequilibrio.

Los resultados de impulso-respuesta y descomposición de varianza en el error de predicción, contrariamente a lo que comúnmente se cree, muestran que el salario mínimo y el desempleo urbano no inciden sustancialmente sobre la ocupación generada en la economía informal; es decir, el comportamiento futuro de la variable Ocif es atribuible, principalmente, a su propio choque y muy poco a los choques experimentados en el desempleo urbano y en el salario mínimo, más concretamente es una variable altamente independiente de las sorpresas ocurridas en todas las demás variables del sistema. Además, los resultados muestran que el desempleo urbano es una variable cuya varianza es altamente dependiente de las sorpresas en las demás variables del sistema, especialmente de los choques ocurridos en la ocupación de la economía informal y en el PIB.

Los resultados de descomposición de varianza, en primer lugar, prueban la existencia de una débil dependencia de la ocupación informal respecto al desempleo urbano, indicando que efectivamente solo una pequeña parte de los trabajadores formales que pierden su empleo transitan a la informalidad, lo que quiere decir que el canal de conexión entre ocupación informal y desempleo urbano es débil o que el desempleo urbano no es muy útil para el 
pronóstico futuro de Ocif. En segundo lugar, estos hallazgos dejan ver la sustancial incidencia de los choques experimentados en la ocupación informal y en el salario mínimo para explicar la varianza del PIBr. Este resultado pone de manifiesto la formidable importancia que para el país tienen los aportes de las unidades productivas informales en materia de generación de bienes y servicios, ocupación e ingresos. Esto significa que debido a su dinámica propia, la economía informal y la ocupación generada en ella inciden definitivamente en el movimiento del producto y el ingreso nacional. Por último, los resultados de descomposición de varianza sugieren una sobreestimación del impacto del salario mínimo sobre la ocupación informal.

En línea con los resultados de descomposición de varianza, los de impulso-respuesta también comprueban un efecto débil del desempleo urbano sobre ocupación producida en la economía informal. Con este resultado se reitera la observación de que solo una pequeña parte de los trabajadores formales que pierden su empleo pasan a engrosar la ocupación informal, lo cual es enteramente consistente con la hipótesis expuesta en este trabajo, según la cual la existencia de la ocupación informal se debe principalmente al hecho de que la economía formal históricamente no ha tenido la capacidad suficiente para absorber un alto porcentaje de la población en edad de trabajar.

Como se manifestó en la sección "Causas estructurales e históricas de la ocupación informal", estos resultados econométricos significan que la persistencia de la ocupación creada en este tipo de economía no puede ser atribuida sustancialmente al nivel de desempleo urbano provocado por los altos costos asociados al salario mínimo, sobre todo cuando se ignoran factores de tipo estructural de la economía y factores de tipo históricos asociados con el desarrollo económico del país. Así, adicional al factor de las debilidades de política pública económica para la economía informal, junto con el bajo impacto que tiene el crecimiento económico sobre el empleo formal, se destacan los factores estructurales relacionados con la falta de capacidad de la economía en su conjunto para absorber, por lo menos, un alto porcentaje de fuerza de trabajo, factor que simultáneamente se encuentra asociado tanto a la dimensión del mercado interno nacional como a los factores relacionados con el patrón histórico que se fue configurando con el proceso de desarrollo del capitalismo colombiano en los últimos cien años, junto al cual, en los diferentes períodos, se fue gestando y consolidando un contingente de masa popular 
de baja calificación laboral (cuenta propia) sin posibilidades de acceso a la economía formal, que como se ha visto, hoy como hace sesenta años, permanecen y tienen gran peso en la economía nacional.

En resumen, el resultado de más relevancia derivado de los análisis de descomposición de varianza y de impulso respuesta es la evidencia de choques e impulsos moderados y tenues que exhibe el salario mínimo para explicar los movimientos (la varianza) de la ocupación causada en el ámbito de la economía informal, evidencia que contradice los planteamientos que le atribuyen a esta variable el mayor peso en la explicación de los niveles de ocupación dentro de la economía informal, así como el desempleo asociado a la economía formal, que de paso permite hacer de ella la argumentación más importante y recurrente para justificar medidas de política económica orientadas a reducir el salario mínimo como tratamiento para atacar tales problemas. En materia de política, este resultado sugiere que las medidas económicas de política sustentadas en la reducción del salario mínimo probablemente tendrán un efecto muy limitado, resultando no ser tan efectivas para disminuir significativamente la ocupación en la economía informal, como ha ocurrido hasta ahora. Es esto justamente lo que observa un organismo como la OCDE para señalar los pobres resultados que en esta materia ha obtenido el Gobierno colombiano en los últimos 20 años, pese a los esfuerzos realizados.

Finalmente, los resultados obtenidos también contribuyen a explicar cómo la ocupación originada en la economía informal hunde sus raíces en la estructura histórica que se fue formando a lo largo del proceso de desarrollo y el crecimiento de la economía del país. Por supuesto, desde la perspectiva de los países latinoamericanos y algunas economías desarrolladas, esto no es algo distintivo de Colombia. 


\section{REFERENCIAS}

Albrecht, J., Navarro, L., \& Vroman, S. (2008). The effects of labor market policies in an economy with an informal sector. Georgetown University.

Alcaraz, C., \& García, R. (2006). Cambios en la composición del empleo y evolución de la productividad del trabajo en el sector externo formal de la economía mexicana: 2000-2005 (Documento Número 2006-03). Banco de México. https://doi.org/10.36095/banxico/di.2006.03

Arango, A. C., \& Pachón, A. (2004). The minimum wage in Colombia: Holding the middle with a bite on the poor (Borradores de Economía n. ${ }^{\circ} 280$ ). Banco de la República.

Arango, L. E., \& Flórez, L. A. (2017). Informalidad laboral y elementos para un salario mínimo diferencial por regiones en Colombia (Borradores de Economía n. ${ }^{\circ}$ 1023). Banco de la República. http://www.banrep. gov.co/sites/default/files/publicaciones/archivos/borradores_de_ economia_1023.pdf

Ayala, J. (2000). Instituciones y economía. Fondo de Cultura Económica.

Bernal, R., Eslava, M., Meléndez, M., \& Pinzón, A. (2017). Switching from payroll taxes to corporate income taxes: Firms' employment and wages after the Colombian 2012 Tax Reform (IDB Technical Note n. 1268). Inter-American Development Bank.

Bernanke, B. S. (2003). The jobless recovery: Remarks at the Global Economic and Investment Outlook Conference, Carnegie Mellon University, Pittsburgh, Pennsylvania. The Federal Reserve Board. https://www. federalreserve.gov/boarddocs/speeches/2003/200311062/default. htm

Bértola, L., \& Ocampo, J. A. (2016). El desarrollo económico de América Latina desde la independencia. Fondo de Cultura Económica.

Bonilla, S. (2011). Estructura económica y desempleo en Colombia: un análisis VEC. Sociedad y Economía, 20, 99-124.

Bosh, M. \& Maloney, W. (2008). Cyclical movements in unemployment and informality in developing countries (Policy Research Working Paper 4648). The World Bank. https://doi.org/10.1596/1813-9450-4648 
Bourguignon, F. (1979). Pobreza y dualismo en el sector urbano de las economías en desarrollo: el caso colombiano. Revista Desarrollo y Sociedad, 1, n. d. https://doi.org/10.13043/dys.1.2

Camacho, A., \& Conover, E. (2010). Misallocation and productivity in Colombia's manufacturing industries (Research Department Publications 4654). Inter-American Development Bank. https://doi. org/10.2139/ssrn.1817206

Cherif, R., Hasanov, F., \& Wang, L. (2018). Sharp instrument: A stab at identifying the causes of economic growth (IMF Working Papers). IMF. https://www.imf.org/en/Publications/WP/Issues/2018/05/21/ Sharp-Instrument-A-Stab-at-Identifying-the-Causes-of-EconomicGrowth-45879 https://doi.org/10.5089/9781484357170.001

Clavijo, S. (2009). Productividad, crecimiento y mercado laboral: perspectivas del período 2008- 2009 (Centro de Estudios Económicos, Informe semanal 1004). ANIF.

Clavijo, S., \& Fandiño, A. (2015). Productividad multifactorial y crecimiento de largo plazo en Colombia (Centro de Estudios Económicos, Informe Semanal 1266). ANIF.

Comisión Europea [CE], Fondo Monetario Internacional [FMI], Organización de Cooperación y Desarrollo Económico [OCDE], Organización de las Naciones Unidas [ONU], \& Banco Mundial [BM]. (2016). Sistema de Cuentas Nacionales 2008. CE/FMI/OCDE/ONU/BM.

Departamento Administrativo Nacional de Estadística [DANE]. (2019). Gran Encuesta Integrada de Hogares, cuarto trimestre, 2019. https://www. dane.gov.co/index.php/estadisticas-por-tema/mercado-laboral/ empleo-y-desempleo

Departamento Administrativo Nacional de Estadística [DANE]. (2020). Boletín técnico, Encuesta de Micronegocios, EMICRON, enero-octubre de 2019. https://www.dane.gov.co/index.php/estadisticas-por-tema/ mercado-laboral/micronegocios

Departamento Nacional de Planeación [DNP]. (2019). Documento CONPES 3956 sobre Política de Formalización Empresarial. DNP. https:// colaboracion.dnp.gov.co/CDT/Conpes/Econ\%C3\%B3micos/3956.pdf Enders, W. (2004). Applied econometric time series. John Wiley and Sons. 
Eslava, M., Haltiwanger, J., Kugler, A., \& Kugler, M. (2004). The effects of structural reforms on productivity and profitability enhancing reallocation: Evidence from Colombia. Journal of Development Economics, 75(2), 333-371. https://doi.org/10.1016/j. jdeveco.2004.06.002

Farné, S., \& Rodríguez, D. (2013). ¿Bajar los impuestos al trabajo genera empleo? Ley 1607 de 2012 de reforma tributaria en Colombia (Cuadernos de trabajo n. ${ }^{\circ}$ 14, Departamento de Seguridad Social y Mercado de Trabajo). Universidad Externado de Colombia.

Fedesarrollo (2013). Informe del Mercado Laboral. Marzo de 2013. Fedesarrollo. http://www.repository.fedesarrollo.org.co/bitstream/ handle/11445/3383/IML_Marzo_2013

Fernández, C., \& Villar, L. (2016). The impact of lowering the payroll tax on informality in Colombia (Working paper.$^{\circ}$ 72). Fedesarrollo. http:// hdl.handle.net/11445/3300

Foro Económico Mundial (2017). The global competitiveness report 20172018. World Economic Forum.

García, J. (1999). Seguridad social, pobreza y sector informal en América Latina (Tesis doctoral, Universidad Complutense de Madrid). Repositorio Universidad Complutense de Madrid.

Garlati, P. (2019). Impuestos a la nómina, informalidad y salario mínimo. Carta Financiera, 2019(1).

Gaviria, A. (2005). La reforma laboral de 2002: ¿funcionó o no?. Coyuntura Económica, junio, 73-103. https://www.repository.fedesarrollo.org. co/bitstream/handle/11445/946/Co_Eco_Junio_2005_Gaviria. pdf? sequence $=2 \&$ isAllowed $=y$

Granger, C., \& Newbold, P. (1974). Spurious regressions in econometrics. Journal of Econometrics, 2(2), 111-120. https://doi. org/10.1016/0304-4076(74)90034-7

Groshen, E. L., \& Potter, S. (2003). Has structural change contributed to a jobless recovery. Current Issues in Economics and Finance, 9(8), 1-7. https://www.newyorkfed.org/research/current_issues/ci9-8.html

International Labour Organisation [ILO]. (2012). Measuring informality: A statistical manual on the informal sector and informal employment. ILO. 
Kalmanovitz, S. (1983). El desarrollo tardío del capitalismo: un enfoque crítico de la teoría de la dependencia. Siglo Veintiuno Ed.

Kalmanovitz, S. (2015). Breve historia económica de Colombia. Universidad de Bogotá Jorge Tadeo Lozano.

Kugler, A., M., Kugler, M. D., \& Herrera-Prada, L. O. (2017). Do payroll tax breaks stimulate formality? Evidence from Colombia's Reform (NBER Working Papers n. ${ }^{\circ}$ 23308). National Bureau of Economic Research. https://doi.org/10.3386/w23308

Lee, Y., \& Rudick, B. (2006). Employment growth, job creation, and job destruction in Ohio. Federal Reserve Bank of Cleveland. https://doi. org/10.26509/frbc-wp-200624

Lesmes, J. (2014.) Progreso tecnológico y desempleo en Colombia: una aproximación desde los modelos de búsqueda. Revista Desarrollo y Sociedad, 73(1), 71-110. https://doi.org/10.13043/dys.73.3

Lütkepohl, H. (2005). New introduction to multiple time series analysis. Springer. https://doi.org/10.1007/978-3-540-27752-1

Maloney, W., \& Núñez, J. (2004). Measuring the impact of minimum wages. Evidence from Latin America. En Law and employment: Lessons from Latin America and the Caribbean (pp. 109-130). University of Chicago Press. https://doi.org/10.7208/chicago/9780226322858.003.0002

Mondragón, C., Peña, X., \& Wills, D. (2010). Labor market rigidities and informality in Colombia. Economía. Latin American and Caribbean Economic Association (LACEA). https://doi.org/10.1353/ eco.2010.0009

Neusser, K. (2016). Time series econometrics. Springer. https://doi. org/10.1007/978-3-319-32862-1

Nieto, V. (2015). Una nota sobre la evolución de la productividad total factorial en el sector manufacturero (1974-2012) (Archivos de Economía n. ${ }^{\circ}$ 015811). Departamento Nacional de Planeación.

North, D. C. (1993). Instituciones, cambio institucional y desempeño económico. Fondo de Cultura Económica.

Ocampo, J. A. (comp.). (2015). Historia económica de Colombia (cuarta ed.). Fondo de Cultura Económica.

Organisation for Economic Co-operation and Development [OECD]. (2016). OECD reviews of labour market and social policies: Colombia 2016. OECD. https://doi.org/10.1787/9789264244825-en 
Organisation for Economic Co-operation and Development [OECD].

(2017). OECD economic surveys: Colombia 2017. OECD. http://dx.doi. org/10.1787/eco_surveys-col-2017

Organización para la Cooperación y el Desarrollo Económicos [OCDE]. (2007). Manual sobre la medición de la economía no observada. OCDE/ Comunidad Andina.

Organización para la Cooperación y el Desarrollo Económicos [OCDE]. (2019). Estudios económicos de la OCDE: Colombia 2019. OECD. https://doi.org/10.1787/805f2a79-es

Organización Internacional del Trabajo [OIT]. (2002). Informe VI. El trabajo decente y la economía informal. $90 .^{\circ}$ Reunión de la Conferencia Internacional del Trabajo. OIT. https://www.ilo.org/public/spanish/ standards/relm/ilc/ilc90/pdf/rep-vi.pdf

Pérez, F. (2007a). La paradoja del crecimiento económico sin empleo (Documentos técnicos sobre mercado laboral). DANE.

Pérez, F. (2007b, septiembre). Crecimiento y desempleo en cuatro actos. UNPeriódico, 104, 5-6.

Pineda-Duque, J. (2015). Colombia: el sesgo anti laboral del modelo de desarrollo y las políticas de formalización. Cuadernos del Cendes, 32(89), 103-139.

Rhenals, R. (2009). ¿Es alto el salario mínimo en Colombia?: una comparación internacional. Perfil de Coyuntura Económica, 13, 97-145.

Santa-María, M., García, F., \& Mujica, A. (2009). Los costos no salariales y el mercado laboral: impacto de la reforma a la salud en Colombia (Working Paper n. ${ }^{\circ} 43$ ). Fedesarrollo. https://www.repository. fedesarrollo.org.co/handle/11445/252

Sunkel, O., \& Paz, P. (1982). El subdesarrollo latinoamericano y la teoría del desarrollo. Siglo Veintiuno Ed.

Tovar, B. (1984). La intervención económica del Estado en Colombia, 19141936. Fondo de Promoción de la Cultura del Banco Popular.

Trapé, A. (2007). Informes de coyuntura por áreas. Observatorio de Coyuntura Económica Internacional, Universidad Nacional del Cuyo. 


\section{ANEXO 1. PRUEBAS DE RAÍCES UNITARIAS}

Null Hypothesis: OCIF has a unit root Exogenous: Constant, Linear Trend Lag Length: 6 (Fixed)

\begin{tabular}{lccc}
\hline \hline & 1-Statistic & Prob." \\
\hline \hline Augmented Dickey-Fuller test statistic & -1.041517 & 0.9306 \\
\hline Test critical values: & $1 \%$ level & -4.096614 & \\
& $5 \%$ level & -3.476275 & \\
& $10 \%$ lewal & -3.165610 & \\
\hline \hline
\end{tabular}

Null Hypothesis: DSU has a unit root Exogenous: Constant, Linear Trend Lag Length: 2 (Fived)

\begin{tabular}{lccc}
\hline \hline & & & \\
\hline \hline Augmented Dickey-Fuller test statistic & -2.749804 & 0.2206 \\
\hline Test critical values: & $1 \%$ level & -4.088713 & \\
& $5 \%$ level & -3.472558 & \\
& $10 \%$ lavel & -3.163450 & \\
\hline \hline
\end{tabular}

Null Hypothesis: SMR hes a unit roo Exogenous: Constant, Linear Trend Exogenous: Constant,

\begin{tabular}{llll} 
& & & \\
\hline \hline Augmented Dickey-Fuller tost statistic & t-Statistio & Prob.* \\
\hline & $1 \%$ leval & -2.749962 & 0.2206 \\
\hline & $5 \%$ level & -4.092547 & \\
& $10 \%$ lewel & -3.474363 & \\
& & -3.164499 & \\
\hline
\end{tabular}

Null Hypothesis: EMF has a unit root

Exogenous: Constant, Linear Trend

Lag Length: 6 (Fixed)

\begin{tabular}{lccc}
\hline \hline & & & \\
\hline Augmented Dickey-Fuller test statistic & -3.146667 & 0.1040 \\
\hline Test critical values: & $1 \%$ level & -4.096614 & \\
& $5 \%$ level & -3.476275 & \\
& $10 \%$ level & -3.165610 & \\
\hline \hline
\end{tabular}

Null Hypothesis: ECM has a unit rool

Exogenous: Constant, Linear Trend

Lag Length: 3 (Fixed)

\begin{tabular}{lccc}
\hline \hline & & & \\
\hline \hline Augmented Dickey-Fuller test statistic & t-Statistic & Prob.* \\
\hline Test critical values: & $1 \%$ level & -2.041226 & 0.5690 \\
& $5 \%$ level & -4.090602 & \\
& $10 \%$ level & -3.473447 & \\
& -3.163967 & \\
\hline \hline
\end{tabular}

Null Hypothesis: PIBR has a unit root

Exocenous: Constant, Linear Trend

Lag Length: O (Automatic - based on SIC, maxlag=11)

\begin{tabular}{lccc}
\hline \hline & & & \\
\hline \hline & & & \\
Augmented Dickey-Fuller test statistic & Prob.* \\
\hline Test critical values: & $1 \%$ level & -0.587341 & 0.9768 \\
& $5 \%$ level & -4.085092 & \\
& $10 \%$ level & -3.470851 & \\
& & -3.162458 & \\
\hline
\end{tabular}

Null Hypothesis: D(OCIF) has a unit root

Exogenaus: Constant, Linear Trend

Lag Length: 6 (Fixed)

\begin{tabular}{lccc}
\hline & & t-Statistic & Prab." \\
\hline \hline Augmented Dickey-Fuller test statistic & -3.505724 & 0.0467 \\
\hline & $1 \%$ level & -4.098741 & \\
& $5 \%$ level & -3.477275 & \\
& $10 \%$ level & -3.166190 & \\
\hline \hline
\end{tabular}

"Mackinnon (1996) one-sided p-values.

Null Hypothesis: D(DSU) has a unit root

Exogenous: Constant, Linear Trend

Lag Length: 3 3 Fixad)

\begin{tabular}{lccc}
\hline \hline & & tStatistic & Prob." \\
\hline Augnented Dickey Fuler test statistic & -3.753627 & 0.0250 \\
\hline Test critical values: & $1 \%$ level & -4.092547 & \\
& $5 \%$ level & -3.474363 & \\
& $10 \%$ level & -3.164499 & \\
\hline \hline
\end{tabular}

Null Hypothesis: D(SMR) has a unit root

Exogenous: Constant, Linear Trend

Lag Length: 3 (Automatic - based on SIC, madag=11)

\begin{tabular}{lccc}
\hline & & t-Statistic & Prob." \\
\hline Augmented Dickey-Fuller test statistic & -3.559890 & 0.0407 \\
\hline Test critical values: & $1 \%$ level & -4.092547 & \\
& $5 \%$ level & -3.474363 & \\
& $10 \%$ level & -3.164499 & \\
\hline \hline
\end{tabular}

Null Hypothesis: D(EMF) has a unit root

Exogenous: Constant Linear Trend

Lag Length: 6 (Fixed)

\begin{tabular}{lcrc}
\hline & & & \\
\hline Augmented Dickey-Fuller test statistic & -4.404970 & 0.0041 \\
\hline Test critical values: & $1 \%$ level & -4.098741 & \\
& $5 \%$ level & -3.477275 & \\
& $10 \%$ level & -3.166190 & \\
\hline \hline
\end{tabular}

Null Hypothesis: D(ECM) has a unit root

Exogenous: Constant, Linear Trend

Lag Length: 2 (Fbed)

\begin{tabular}{lccc}
\hline \hline & & & \\
\hline \hline Augmented Dickey-Fuller test statistic & -9.405841 & 0.0000 \\
\hline Test critical values: & $1 \%$ level & -4.090602 & \\
& $5 \%$ level & -3.473447 & \\
& $10 \%$ level & -3.163967 & \\
\hline \hline
\end{tabular}

Null Hypothesis: D(PIBR) has a unit root

Exogenous: Constant, Linear Trend

Lag Length: 0 (Automatic - based on SIC, maxdag=11)

\begin{tabular}{lccc}
\hline \hline & t-Statistic & Prob.* \\
\hline \hline Augmented Dickey-Fuller test statistic & -9.493491 & 0.0000 \\
\hline Test critical values: & $1 \%$ level & -4.086877 & \\
& $5 \%$ level & -3.471693 & \\
& $10 \%$ level & -3.162948 & \\
\hline \hline
\end{tabular}

"Mackinnon (1996) one-sided p-values 


\section{ANEXO 2. TEST DE COINTEGRACIÓN DE JOHANSEN}

Date: 04/07/20 Time: 13:27

Sample (adjusted): 2001Q3 2019Q4

Included observations: 74 after adjustments

Trend assumption: Linear deterministic trend

Series: OCIF DSU SMR EMF ECM PIBR

Lags interval (in first differences): 1 to 1

Unrestricted Cointegration Rank Test (Trace)

\begin{tabular}{ccccc}
\hline \hline $\begin{array}{c}\text { Hypothesized } \\
\text { No. of CE(s) }\end{array}$ & Eigenvalue & $\begin{array}{c}\text { Trace } \\
\text { Statistic }\end{array}$ & $\begin{array}{c}0.05 \\
\text { Critical Value }\end{array}$ & Prob. ${ }^{* *}$ \\
\hline \hline None * & 0.528904 & 99.37419 & 95.75366 & 0.0275 \\
At most 1 & 0.278931 & 43.67484 & 69.81889 & 0.8702 \\
At most 2 & 0.139596 & 19.47528 & 47.85613 & 0.9935 \\
At most 3 & 0.059676 & 8.349115 & 29.79707 & 0.9955 \\
At most 4 & 0.046691 & 3.795804 & 15.49471 & 0.9193 \\
At most 5 & 0.003473 & 0.257438 & 3.841466 & 0.6119 \\
\hline \hline
\end{tabular}

Trace test indicates 1 cointegrating eqn(s) at the 0.05 level

* denotes rejection of the hypothesis at the 0.05 level

**MacKinnon-Haug-Michelis (1999) p-values

Unrestricted Cointegration Rank Test (Maximum Eigenvalue)

\begin{tabular}{ccccc}
\hline $\begin{array}{c}\text { Hypothesized } \\
\text { No. of CE(s) }\end{array}$ & Eigenvalue & $\begin{array}{c}\text { Max-Eigen } \\
\text { Statistic }\end{array}$ & $\begin{array}{c}0.05 \\
\text { Critical Value }\end{array}$ & Prob. $^{\text {** }}$ \\
\hline \hline None ${ }^{*}$ & 0.528904 & 55.69935 & 40.07757 & 0.0004 \\
At most 1 & 0.278931 & 24.19956 & 33.87687 & 0.4411 \\
At most 2 & 0.139596 & 11.12617 & 27.58434 & 0.9621 \\
At most 3 & 0.059676 & 4.553310 & 21.13162 & 0.9981 \\
At most 4 & 0.046691 & 3.538366 & 14.26460 & 0.9046 \\
At most 5 & 0.003473 & 0.257438 & 3.841466 & 0.6119 \\
\hline \hline
\end{tabular}

Max-eigenvalue test indicates 1 cointegrating eqn(s) at the 0.05 level

* denotes rejection of the hypothesis at the 0.05 level

${ }^{* *}$ MacKinnon-Haug-Michelis (1999) p-values

\section{ANEXO 3. SELECCIÓN LONGITUD DE REZAGOS PARA EL MVCE}

VAR Lag Order Selection Criteria

Endogenous variables: OCIF DSU SMR EMF ECM PIBR

Exogenous variables:

Date: 05/02/20 Time: 16:30

Sample: 2001Q1 2019Q4

Included observations: 69

\begin{tabular}{ccccccc}
\hline \hline Lag & LogL & LR & FPE & AIC & SC & HQ \\
\hline \hline 1 & 997.4740 & NA & $3.18 \mathrm{e}-20$ & -27.86881 & $-26.70319^{\star}$ & -27.40637 \\
2 & 1040.319 & 70.78715 & $2.66 \mathrm{e}-20$ & -28.06721 & -25.73597 & -27.14233 \\
3 & 1090.642 & 74.39022 & $1.85 \mathrm{e}-20$ & -28.48237 & -24.98550 & -27.09504 \\
4 & 1164.050 & 95.74991 & $6.97 \mathrm{e}-21$ & -29.56666 & -24.90418 & -27.71690 \\
5 & 1231.445 & $76.18580^{\star}$ & $3.40 \mathrm{e}-21^{\star}$ & $-30.47667^{\star}$ & -24.64856 & $-28.16446^{\star}$ \\
6 & 1260.154 & 27.46042 & $5.73 \mathrm{e}-21$ & -30.26532 & -23.27160 & -27.49068 \\
7 & 1299.740 & 30.98026 & $8.46 \mathrm{e}-21$ & -30.36926 & -22.20992 & -27.13218 \\
\hline \hline
\end{tabular}

* indicates lag order selected by the criterion

LR: sequential modified LR test statistic (each test at $5 \%$ level)

FPE: Final prediction error

AIC: Akaike information criterion

SC: Schwarz information criterion

HQ: Hannan-Quinn information criterion 


\section{ANEXO 4. RESULTADOS DEL MODELO VECTORIAL DE CORRECCIÓN DE ERRORES}

\begin{tabular}{|c|c|c|c|c|c|c|}
\hline 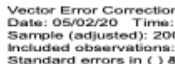 &  & & & & & \\
\hline Cointegrating $\mathrm{Eq}_{\mathrm{q}}$ & CoimEat & & & & & \\
\hline $\begin{array}{l}\text { ocif(-1) } \\
\text { Dsu(-1) }\end{array}$ & 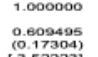 & & & & & \\
\hline SMR(-1) & 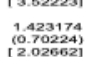 & & & & & \\
\hline $\operatorname{EMF(-1)}$ & 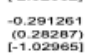 & & & & & \\
\hline ECM $(-1)$ & 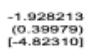 & & & & & \\
\hline PraR(-1) & 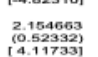 & & & & & \\
\hline ATREND(0101) & 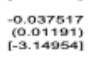 & & & & & \\
\hline$\frac{c}{\text { ror Correction: }}$ & 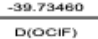 & D(DSU) & D(SMR) & D(EMF) & $D(E C M)$ & D(PBIR) \\
\hline CoimtEq1 & 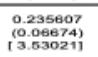 & 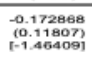 & 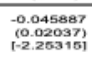 & 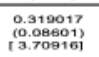 & 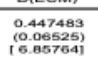 & 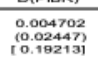 \\
\hline DROCIF(-1) & 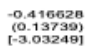 & 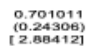 &  &  & 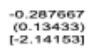 & 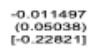 \\
\hline D(OCIF $(-2))$ & 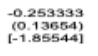 & 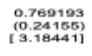 & 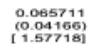 & 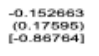 & 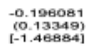 & 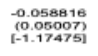 \\
\hline Drocif(-3) &  & 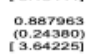 & 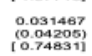 & 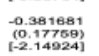 & 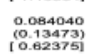 & 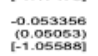 \\
\hline DrOCIF(-4) & 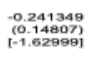 & 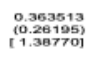 & 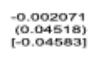 & 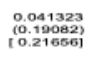 & 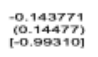 & 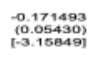 \\
\hline D(Dsu(-1) & 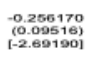 & 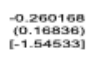 & 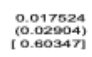 & 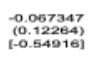 & 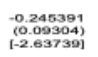 & 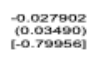 \\
\hline D(DSu (-2)) & 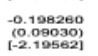 & 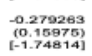 & 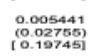 & 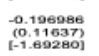 & 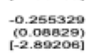 & 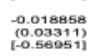 \\
\hline o(osu(-3) & 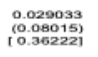 &  & 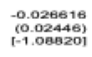 & 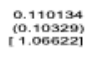 & 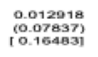 &  \\
\hline D(DSU(-4) & 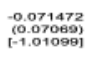 & 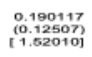 & 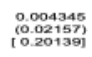 & 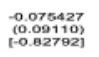 & 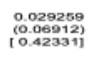 & 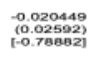 \\
\hline D(sMRR(-1)) & 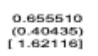 & 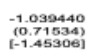 & 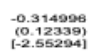 & 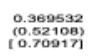 & 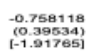 & 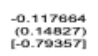 \\
\hline D(SMRR(-2)) & 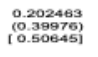 & 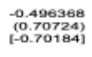 & 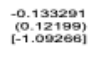 & 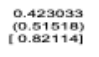 & 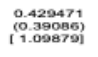 & 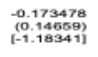 \\
\hline D(SMRR(-3)) & 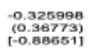 & 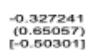 & 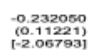 & 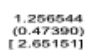 & 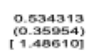 & 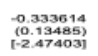 \\
\hline D(SMRR(-4)) & 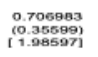 & 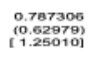 & 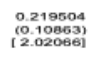 & 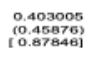 & 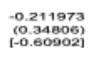 & 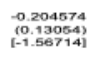 \\
\hline D(EMF(-1)) & 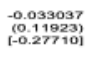 & 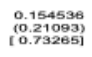 & 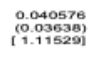 & 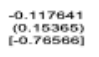 & 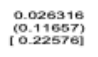 & 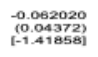 \\
\hline D(EMF(-2) &  & 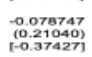 & 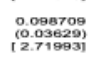 &  & 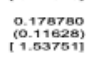 & 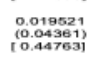 \\
\hline D(EMF(-3)) & 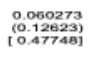 & 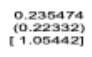 &  & 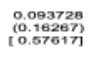 &  & 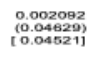 \\
\hline$D(E M F(-4))$ & 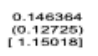 & 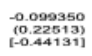 & 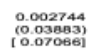 & 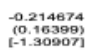 & 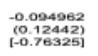 & 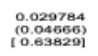 \\
\hline$D($ ECM $(-1))$ & 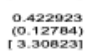 & 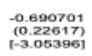 & 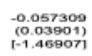 &  & 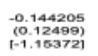 & 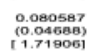 \\
\hline D(ECM(-2)) &  & 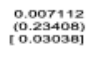 & 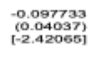 & 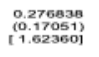 & 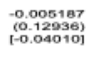 & 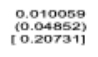 \\
\hline D(ECM(-3)) & 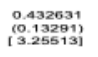 & 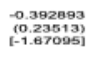 & 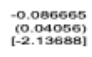 & 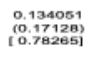 & 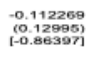 & 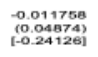 \\
\hline$D(E C M(-4))$ & 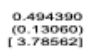 & 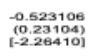 & 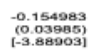 & 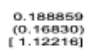 & 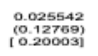 & 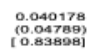 \\
\hline D(PIBR(-1)) & 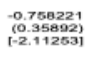 & 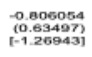 & 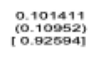 & 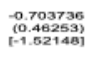 & 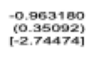 & 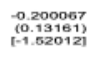 \\
\hline D(PIBR(-2)) &  & 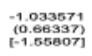 & 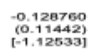 & 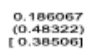 & 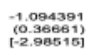 & 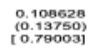 \\
\hline D(PABR(-3)) & 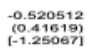 & 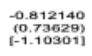 & 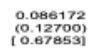 & 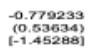 & 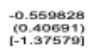 & 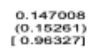 \\
\hline D(PIBR(-4)) & 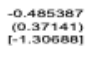 & 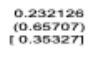 &  & 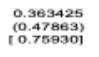 & 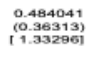 & 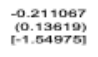 \\
\hline c & 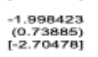 &  & 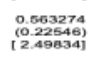 & 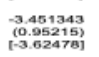 & 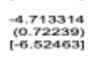 & 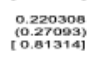 \\
\hline Esv & 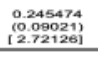 & 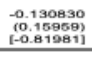 & 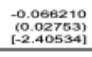 & 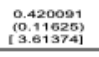 & 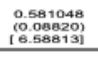 & 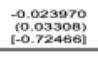 \\
\hline  & $\begin{array}{l}\text { o.750.027 } \\
0.0110602 \\
0.01063\end{array}$ &  & 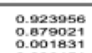 & 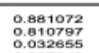 & 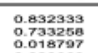 & 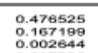 \\
\hline 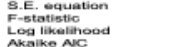 & 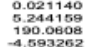 & 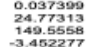 & 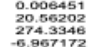 & 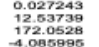 & 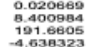 & 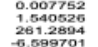 \\
\hline 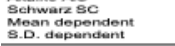 & 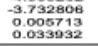 & 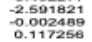 & 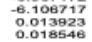 & 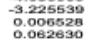 & 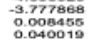 & 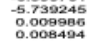 \\
\hline 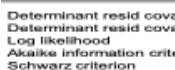 & & 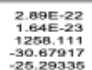 & & & & \\
\hline
\end{tabular}




\section{ANEXO 5. PRUEBA SOBRE LAS RESTRICCIONES DE LOS COEFICIENTES DEL VECTOR COINTEGRANTE}

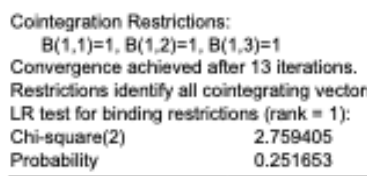

Cointegration Restrictions:

$B(1,4)=-1, B(1,5)=-1, B(1,6)=1$

Convergence achieved after 28 iterations

Restrictions identify all cointegrating vectors

LR test for binding restrictions (rank $=1$ ):

Chi-square(2) 8.583709

Probabi ty $\quad 0.013680$

\section{ANEXO 6. PRUEBAS DE RESTRICCIONES SOBRE LOS COEFICIENTES DE VELOCIDAD DE AJUSTE}

\section{Cointegration Restrictions:$$
A(1,1)=0
$$

Convergence achieved after 19 iteratio... Not all cointegrating vectors are identifi... LR test for binding restrictions (rank $=1 \ldots$... Chi-square(1)

11.63390

Probability

\subsection{8}

\section{Cointegration Restrictions:

$$
A(2,1)=0
$$

Convergence achieved after 15 iteratio... Not all cointegrating vectors are identifi... LR test for binding restrictions (rank $=1 \ldots$. Chi-square(1)

\section{Cointegration Restrictions:}

$$
A(3,1)=0
$$

Convergence achieved after 17 iteratio... Not all cointegrating vectors are identifi... LR test for binding restrictions (rank $=1 \ldots$ Chi-square(1)

6.761428 Probability 0.009315
Cointegration Restrictions:

$$
\mathrm{A} / 4,1)=0
$$

Convergence achieved after 23 iteratio... Not all cointegrating vectors are identifi... LR test for binding restrictions (rank $=1 \ldots$ Chi-square(1)

Probability 0.000173

\section{Cointegration Restrictions:}

$$
A(5,1)=0
$$

Convergence achieved after 67 iteratio... Not all cointegrating vectors are identifi... LR test for binding restrictions (rank $=1$... Chi-square(1)

36.10028

Probability

0.000000

Cointegration Restrictions:

$$
A(6,1)=0
$$

Convergence achieved after 10 iteratio... Not all cointegrating vectors are identifi... LR test for binding restrictions ( $r a n k=1 \ldots$ Chi-square(1) 0.048253 Probability 0.826132 
ANEXO 7. DESCOMPOSICIÓN DE VARIANZA

\begin{tabular}{|c|c|c|c|c|c|c|c|}
\hline \multicolumn{8}{|c|}{ Variance Decomposition of OCIF: } \\
\hline & & & DSU & SMR & EMF & ECM & PIBR \\
\hline 1 & 0.021140 & 100.0000 & 0.000000 & 0.000000 & 0.000000 & 0.000000 & 0.000000 \\
\hline 2 & 0.028065 & 92.28483 & 1.774329 & 4.050814 & 1.373108 & 0.116344 & 0.400578 \\
\hline 3 & 0.032557 & 87.98889 & 3.260458 & 5.791191 & 1.773492 & 0.824686 & 0.361279 \\
\hline 4 & 0.035068 & 86.66421 & 3.441388 & 6.896556 & 1.641423 & 0.712971 & 0.643455 \\
\hline 5 & 0.038237 & 84.84520 & 2.905359 & 8.604402 & 2.057065 & 0.746740 & 0.841236 \\
\hline 6 & 0.042637 & 83.08095 & 2.336666 & 8.374325 & 1.685208 & 3.785435 & 0.737419 \\
\hline 7 & 0.049146 & 80.97925 & 1.766233 & 10.11557 & 1.315887 & 5.086312 & 0.736745 \\
\hline 8 & 0.054298 & 79.75930 & 1.929768 & 10.02715 & 1.123052 & 6.524495 & 0.636240 \\
\hline 9 & 0.058164 & 80.75054 & 1.719109 & 9.716545 & 0.985961 & 6.258868 & 0.568972 \\
\hline 10 & 0.061548 & 80.40313 & 1.546590 & 10.07435 & 0.885730 & 6.293912 & 0.796294 \\
\hline 11 & 0.064891 & 79.25157 & 1.401312 & 10.50660 & 0.808596 & 7.256076 & 0.775841 \\
\hline 12 & 0.068434 & 77.74220 & 1.359589 & 11.78793 & 0.770268 & 7.483079 & 0.856937 \\
\hline \multicolumn{8}{|c|}{ Variance Decomposition of DSU: } \\
\hline Peri... & S.E. & OCIF & DSU & SMR & EMF & ECM & PIBR \\
\hline 1 & 0.037399 & 0.583271 & 99.41673 & 0.000000 & 0.000000 & 0.000000 & 0.000000 \\
\hline 2 & 0.047614 & 9.265815 & 79.68701 & 4.818689 & 0.078433 & 3.071424 & 3.078626 \\
\hline 3 & 0.056454 & 22.98005 & 62.17162 & 3.428266 & 0.233037 & 2.245647 & 8.941382 \\
\hline 4 & 0.066240 & 34.49150 & 47.95926 & 2.555395 & 0.473463 & 3.364054 & 11.15632 \\
\hline 5 & 0.077286 & 32.14736 & 44.75208 & 5.483955 & 0.722071 & 3.887059 & 13.00747 \\
\hline 6 & 0.086491 & 34.63404 & 41.46200 & 5.721410 & 0.924176 & 3.105695 & 14.15268 \\
\hline 7 & 0.095503 & 37.19156 & 37.20888 & 5.176104 & 0.825202 & 3.187591 & 16.41067 \\
\hline 8 & 0.105553 & 40.92866 & 31.04688 & 5.784 & 0.755418 & 4.073413 & 17.41113 \\
\hline 9 & 0.117945 & 39.71917 & 28.57909 & 8.186765 & 0.616601 & 6.290455 & 16.60792 \\
\hline 10 & 0.126111 & 40.38766 & 27.55251 & 9.210677 & 0.796659 & 5.682213 & 16.37028 \\
\hline 11 & 0.13 & 41.80 & 25.9 & 8.78 & 0.769 & 5.589917 & 17.14013 \\
\hline 12 & 0.141707 & 42.93348 & 23.41302 & 9.037294 & 0.767318 & 5.880198 & 17.96870 \\
\hline \multicolumn{8}{|c|}{ Variance Decomposition of SMR: } \\
\hline Peri... & SE & OCI5 & DSU & SMR & EMF & ECM & PIBR \\
\hline 1 & 0.006451 & 0.161 & 02723 & 552 & 0.000000 & 0.000000 & 0.000000 \\
\hline 2 & 0.008068 & 0.872790 & 0.799352 & 94.29878 & 3.521118 & 0.507460 & 0.000498 \\
\hline 3 & 0.009752 & 0.746311 & 3.750324 & 81.11073 & 10.71086 & 1.438250 & 2.243531 \\
\hline 4 & 0.011098 & 0.924171 & 8.166503 & 74.34430 & 12.84581 & 1.924990 & 1.794233 \\
\hline 5 & 0.013071 & 2.433941 & 7.251037 & 74.83816 & 9.970568 & 3.827532 & 1.678765 \\
\hline 6 & 0.014882 & 4.801980 & 6.002575 & 72.45940 & 11.52239 & 3.793443 & 1.420208 \\
\hline 7 & 0.015817 & 4.7397 & 6.946454 & 70.59254 & 12.59105 & 3.379 & 1.750877 \\
\hline 8 & 0.017369 & 4.97 & 12.01572 & 65.75030 & 12.31006 & 2.815232 & 2.136315 \\
\hline 9 & 0.018921 & 5.23 & 11.65911 & 66.27734 & 11.33269 & 3.21 & 2.283775 \\
\hline 10 & 0.020303 & 7.49 & 10.61761 & 64.98845 & 11.74941 & 3.137 & 2.015028 \\
\hline 11 & 0.021320 & 7.943 & 10.88775 & 63.36598 & 12.36990 & 3.152007 & 2.280387 \\
\hline 12 & 0.022432 & 8.533654 & 13.36750 & 60.45542 & 12.35125 & 2.909191 & 2.382986 \\
\hline Varianc & e Decompos & on of EMF: & & & & & \\
\hline Peri... & S.E. & OCIF & DSU & SMR & EMF & ECM & PIBR \\
\hline 1 & $0 . c$ & 0.823 & 7 & 2 & 3 & 00 & 0.000000 \\
\hline 2 & 0.034452 & 0.562763 & 5.022156 & 4.086018 & 85.52865 & 4.799279 & 0.001133 \\
\hline 3 & 0.040690 & 0.774092 & 4.683903 & 7.042626 & 81.61397 & 4.338597 & 1.546813 \\
\hline 4 & 0.047029 & 0.580617 & 3.899782 & 13.27483 & 76.51869 & 4.558311 & 1.167768 \\
\hline 5 & 0.051769 & 1.078573 & 3. & & 75.10350 & 5.913 & 2.029493 \\
\hline 6 & 0.05 & 2. & 3.387 & 28 & 72.29207 & 6.955591 & 1.818527 \\
\hline 7 & 0.060942 & 2.219562 & 3.575585 & 13.47040 & 71.04874 & 7.948373 & 1.737339 \\
\hline 8 & 0.064637 & 2.011119 & & & 693 & 9.503513 & 2.065483 \\
\hline 9 & 0.068731 & 1.782 & 3.052630 & 14.10 & 70.76327 & 8.425930 & 1.865983 \\
\hline 10 & 0.072 & 1.6 & 2.900 & & 70.3 & 9.57 & 1.772956 \\
\hline 11 & 0.075687 & 1.686024 & 3.245649 & 13.99921 & 69.65699 & 9.677934 & 1.734188 \\
\hline 12 & 0.079423 & 1.654338 & 2.947494 & 15.27002 & 68.35561 & 10.16496 & 1.607586 \\
\hline & & & & & & & \\
\hline Peri. & . & OGIF & DSU & SMR & EMF & ECM & PIBR \\
\hline 1 & & & & & & & \\
\hline 2 & 0. & & & & & & 1.11E-05 \\
\hline 3 & 0.023 & 9.94 & 204 & 62 & 4.233 & 59.8 & 0.355660 \\
\hline 4 & 0.028024 & 18 & 3 & 27 & 83 & 44.07289 & 0.818940 \\
\hline 5 & 0.029823 & & & 19.46656 & 41 & 39.23515 & 3.511542 \\
\hline 6 & 0. & & & & & & 66573 \\
\hline 7 & 0.034095 & 34.65341 & 11.97150 & & 2.425335 & 14 & 3.219889 \\
\hline 8 & 0.036 & & & & & & 2.983313 \\
\hline 9 & 0.038 & & & & & & 2.88 \\
\hline 10 & 0.040 & 40.9 & 14.9 & 38 & 2.020 & 22.6 & 2.785877 \\
\hline 11 & 0.04 & & & & & 20. & 2.564358 \\
\hline 12 & 0.045145 & 44.83633 & 14.71020 & 17.33034 & 1.660317 & 18.99416 & 2.468662 \\
\hline & & & & & & & \\
\hline D. & & & DSU & SMR & EMF & ECM & PIBR \\
\hline 1 & 0 & 3 & & & & & 2633 \\
\hline 2 & 0.010072 & 3 & 41020 & 30823 & 918236 & 8.692544 & 82.04702 \\
\hline 3 & 0.012868 & 6.6577 & 0.344723 & 1.144194 & 4.012743 & 7.422092 & 80.41845 \\
\hline 4 & 0.015 & 10 & & & 3.203489 & 6.104374 & 76.39204 \\
\hline 5 & 0.019311 & 18.30808 & 0.192123 & 5.754081 & 2.517685 & 6.439488 & 66.78855 \\
\hline 6 & 0.022915 & 20.3 & 0.740 & & 1.942167 & 5.722192 & 62.69959 \\
\hline 7 & 0.025767 & 20.78661 & 0.844323 & 10.29040 & 1.550360 & 6.170952 & 60.35736 \\
\hline 8 & 0.028314 & 20.25507 & 0.815496 & 11.91088 & 1.286675 & 6.152663 & 59.57921 \\
\hline 9 & 0. & 19 & 0. & & 1.109 & 5.980 & 58.69621 \\
\hline 10 & 0.033537 & 19.59409 & 0.870965 & 14.79748 & 0.961519 & 6.552374 & 57.22357 \\
\hline 11 & & & & & & 6.70 & 55.59746 \\
\hline 12 & 0.038615 & 19.92710 & 1.016868 & 16.86727 & 0.740528 & 6.991206 & 54.45704 \\
\hline
\end{tabular}

Cholesky Ordering: OCIF DSU SMR EMF ECM PIBR 


\section{ANEXO 8. PRUEBAS ESTADÍSTICAS SOBRE LOS ERRORES DE CORRELACIÓN SERIAL, NORMALIDAD Y DE HETEROSCEDASTICIDAD}

\begin{tabular}{|c|c|c|}
\hline Lags & LM-Stat & Prob \\
\hline 1 & 4121823 & 0.2529 \\
\hline 2 & 32.28221 & 0.6461 \\
\hline 3 & 39.63217 & 0.3112 \\
\hline 4 & 45.65363 & 0.1300 \\
\hline 5 & 33.78853 & 0.5742 \\
\hline 6 & 33.81214 & 0.5731 \\
\hline 7 & 30.64677 & 0.7210 \\
\hline 8 & 42.00313 & 0.2269 \\
\hline
\end{tabular}

Probs from chi-sousre with 36 of.

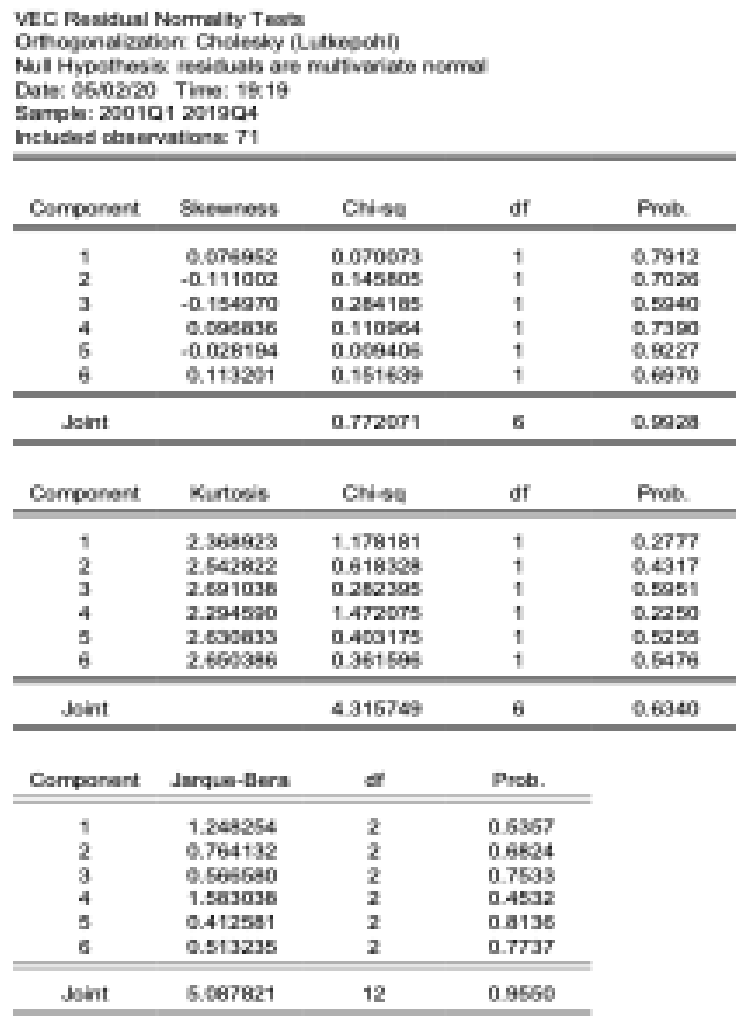


TIEMPO \& ECONOMÍA

Vol. 9 N. ${ }^{\circ} 1$ | Enero - Junio del 2022

pp. 41 - 103

VEC Residual Heiemelosdasticity Tests: No Cross Terms (conly levels and squares)

Dita: 06104/25 Time: 13.54

Sample: 2001Q1 201904

nduded observasons: 71

\begin{tabular}{ccc} 
Joimt teat: & & \\
\hline Chi-sq & of & Prob. \\
\hline \hline 1127.883 & 1082 & 0.2195 \\
\hline
\end{tabular}

Individual components:

\begin{tabular}{|c|c|c|c|c|c|}
\hline Degentante & R-squared & $F(52,18)$ & Prab. & Chi-acis:52) & Prob. \\
\hline resitone 1 & 0.793234 & 1.327963 & 0.2587 & 56.31164 & 0.3165 \\
\hline nec2"res2 & 0.713175 & 0.000683 & 0.6745 & 5063542 & 0.5277 \\
\hline res3"res3 & 0.781444 & 1.237667 & 0.3175 & 55.48251 & 0.3449 \\
\hline resetreas 4 & 0.657812 & 0.665437 & 0.8725 & 46.70468 & 0.6815 \\
\hline ree5"res5 & 0.481224 & 0.321097 & 0.9983 & 34.16587 & 0.9734 \\
\hline resatreas 6 & 0.850415 & $1.96793 \mathrm{~s}$ & 0.0678 & 60.37545 & 0.1488 \\
\hline resa"rea 1 & 0.780396 & $1.295+08$ & 0.3255 & 55.40810 & 0.3474 \\
\hline reej"rest & 0.769563 & 1.155664 & $0.37 \mathrm{se}$ & 54.64511 & 0.3743 \\
\hline ress-ten2 & 0.817224 & 1.547710 & 0.1547 & 58.02287 & 0.2630 \\
\hline reod"res1 & 0.725592 & 0.915304 & 0.5147 & 51.51705 & $0.498 B$ \\
\hline reod"rese 2 & 0.787446 & 1.282383 & 0.2871 & 55.90568 & 0.3303 \\
\hline restreas & 0.602243 & 0.524110 & 0.6 ss & 4275124 & 0.8159 \\
\hline ree5"res1 & 0.725235 & 0.913663 & 0.5165 & 51.49167 & 0.4938 \\
\hline res6"ten2 & 0.721544 & 0.893755 & 0.6327 & $51.25=06$ & 0.5000 \\
\hline res6"tens & 0.748500 & 1.095002 & 0.4947 & 53.14348 & 0.4299 \\
\hline ree5"rest & 0.741974 & 0.995394 & 0.5898 & 5260018 & 0,4475 \\
\hline resatreat 1 & 0.820130 & 1.578315 & 0.1440 & 58.22124 & 0.2589 \\
\hline rees"res2 & 0 . & 1.445983 & 0.1905 & 57.28025 & 0.2555 \\
\hline rees"ress & 0.223039 & 1.615605 & 0.1315 & 58 47838 & 0.2497 \\
\hline resatreas 4 & 0.736748 & 0.968761 & 0.5675 & 5230512 & 0.4619 \\
\hline nees"ress & 0.827127 & 1.650205 & 0.1198 & 5872502 & 0.2426 \\
\hline
\end{tabular}

